\title{
Exploring the nature and extent of normative change in FGM/C in Somaliland
}

\author{
Richard A. Powell \\ Mohamed Yussuf \\ Bettina Shell-Duncan \\ Caroline W. Kabiru \\ Population Council
}

Follow this and additional works at: https://knowledgecommons.popcouncil.org/departments_sbsr-rh

Part of the Demography, Population, and Ecology Commons, Family, Life Course, and Society Commons, Gender and Sexuality Commons, and the Women's Health Commons How does access to this work benefit you? Let us know!

\section{Recommended Citation}

Powell, Richard A., Mohamed Yussuf, Bettina Shell-Duncan, and Caroline W. Kabiru. 2020. "Exploring the nature and extent of normative change in FGM/C in Somaliland," Evidence to End FGM/C: Research to Help Girls and Women Thrive. New York: Population Council. 


\section{Evidence to End FGM/C}

Research to Help Girls and Women Thrive

\section{EXPLORING THE NATURE AND EXTENT OF NORMATIVE CHANGE IN FGM/C IN SOMALILAND}

February 2020 


\section{EXPLORING THE NATURE AND EXTENT OF NORMATIVE CHANGE IN FGM/C IN SOMALILAND}

RICHARD A. POWELL MWAPO HEALTH DEVELOPMENT GROUP

MOHAMED YUSSUF POPULATION COUNCIL

BETTINA SHELL-DUNCAN UNIVERSITY OF WASHINGTON

CAROLINE KABIRU POPULATION COUNCIL 
Evidence to End FGM/C: Research to Help Girls and Women Thrive generates evidence to inform and influence investments, policies, and programmes for ending female genital mutilation/cutting in different contexts. Evidence to End FGM/C is led by the Population Council, Nairobi in partnership with the Africa Coordinating Centre for the Abandonment of Female Genital Mutilation/Cutting (ACCAF), Kenya; the Global Research and Advocacy Group (GRAG), Senegal; Population Council, Nigeria; Population Council, Egypt; Population Council, Ethiopia; MannionDaniels, Ltd. (MD); Population Reference Bureau (PRB); University of California, San Diego (Dr. Gerry Mackie); and University of Washington, Seattle (Prof. Bettina ShellDuncan).

POPULATION COUNCIL Ideas. Evidence. Impact.
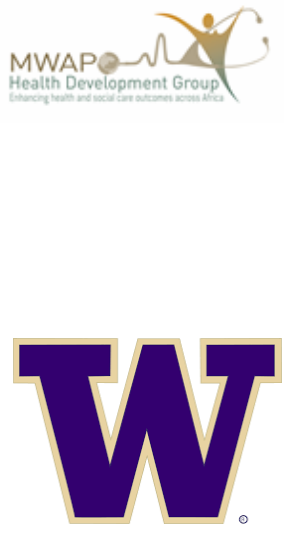

The Population Council confronts critical health and development issues-from stopping the spread of HIV to improving reproductive health and ensuring that young people lead full and productive lives. Through biomedical, social science, and public health research in 50 countries, we work with our partners to deliver solutions that lead to more effective policies, programmes, and technologies that improve lives around the world. Established in 1952 and headquartered in New York, the Council is a nongovernmental, nonprofit organisation governed by an international board of trustees. www.popcouncil.org

Vision: To enhance health and social care outcomes across Africa. Mission: Developing and strengthening adaptive health and social care systems using innovation, scale-up of best practices and evidence-based solutions.

Goals: Improve health and social care systems performance through organizational development and services integration; Strengthen evidence-based solutions through M\&E and Research; and Enhance health and social care systems adaptability through policy reviews, advocacy and communication.

Vision: The University of Washington educates a diverse student body to become responsible global citizens and future leaders through a challenging learning environment informed by cuttingedge scholarship. Discovery is at the heart of our university. We discover timely solutions to the world's most complex problems and enrich the lives of people throughout our community, the state of Washington, the nation and the world. Our values are: Integrity, Diversity, Excellence, Collaboration, Innovation, Respect.

Suggested citation: Richard A. Powell, Mohamed Yussuf, Bettina Shell-Duncan, Caroline Kabiru. 2020. "Exploring the nature and extent of normative change in FGM/C in Somaliland." Evidence to End FGM/C: Research to Help Girls and Women Thrive. New York: Population Council.

This is a working paper and represents research in progress. This paper represents the opinions of the authors and is the product of professional research. This paper has not been peer reviewed, and this version may be updated with additional analyses in subsequent publications. Contact: [richard2powell@yahoo.co.uk].

Please address any inquiries about the Evidence to End FGM/C programme consortium to:

Dr Jacinta Muteshi, Project Director, jmuteshi@popcouncil.org

Funded by:

$\triangle 1 / 2$

This document is an output from a programme funded by UK Aid from the UK government for the benefit of developing countries. However, the views expressed and information contained in it are not necessarily those of, or endorsed by the UK government, which can accept no responsibility for such views or information or for any reliance placed on them. 


\section{Table of Contents}

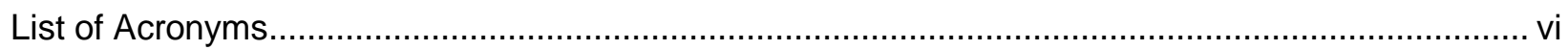

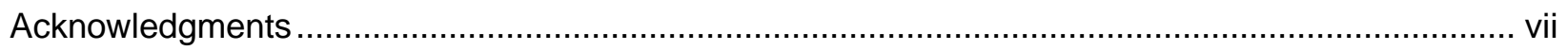

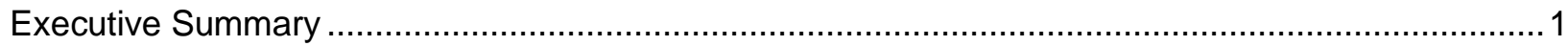

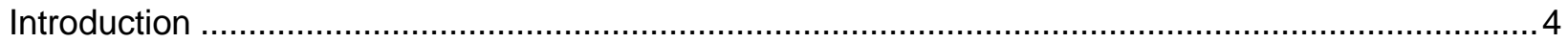

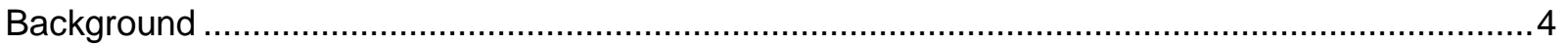

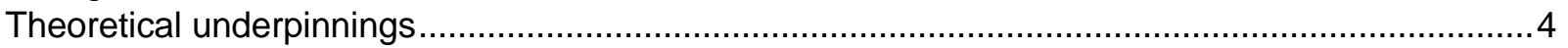

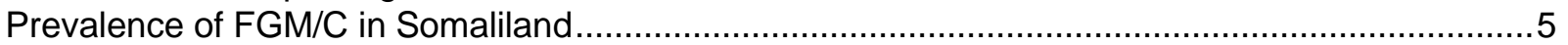

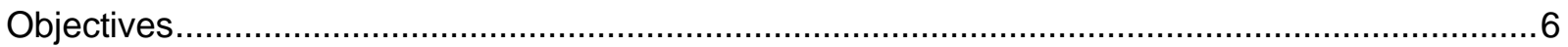

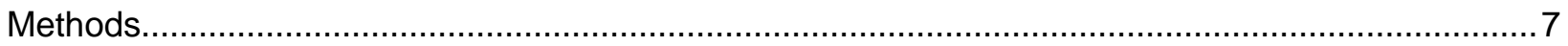

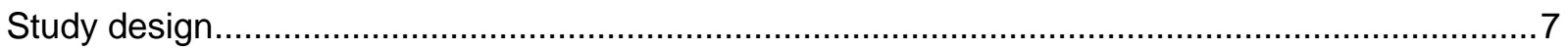

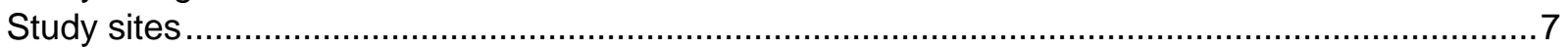

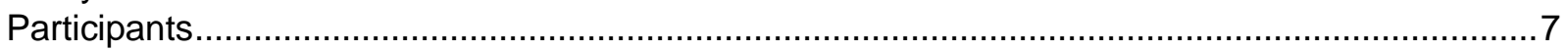

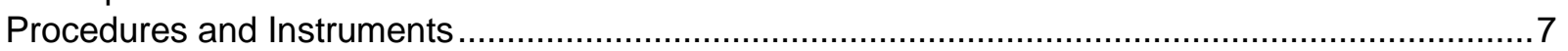

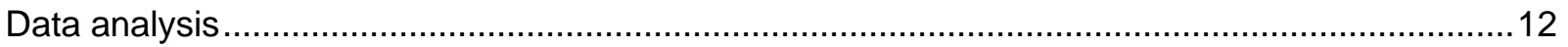

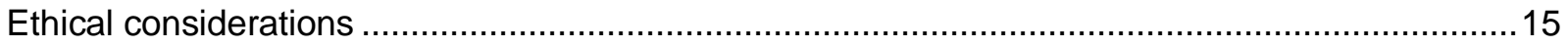

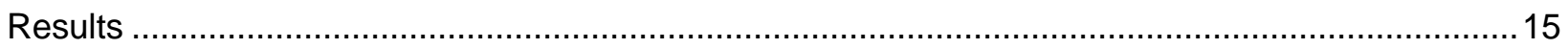

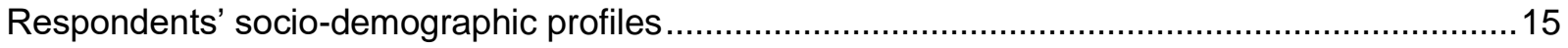

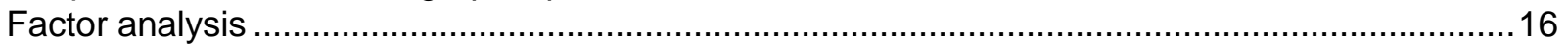

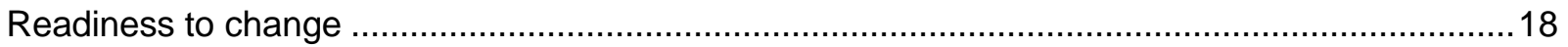

Qualitative findings ..................................................................................................... 18

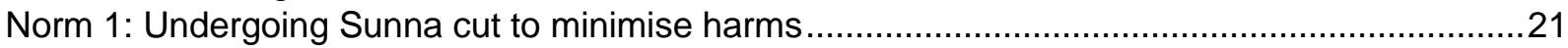

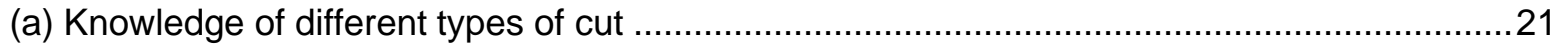

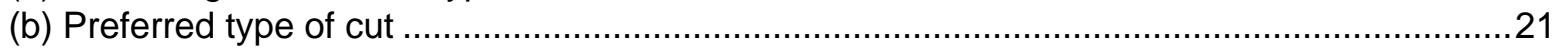

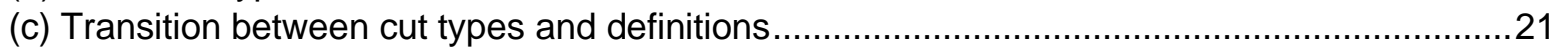

(d) Generational differences in attitudes toward the Sunna ...............................................22

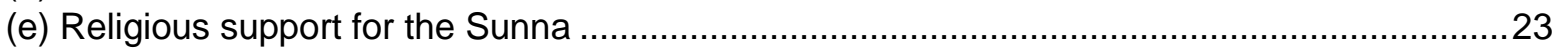

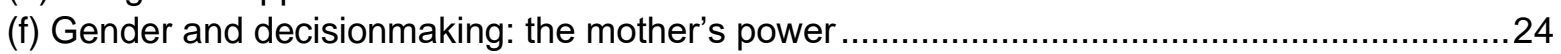

Norm 2: Being cut by a health professional to minimise harm ...............................................2.

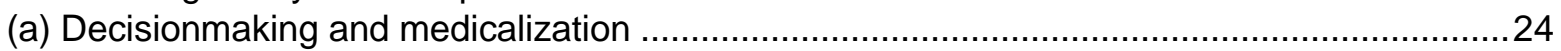

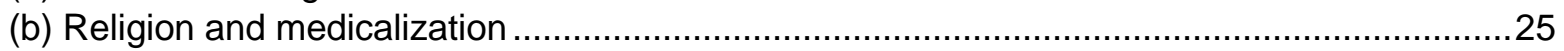

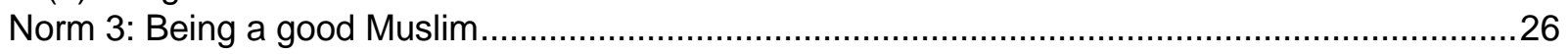

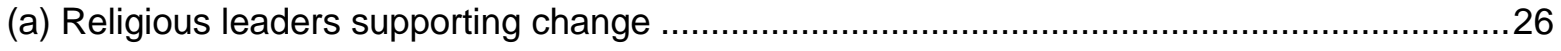

(b) Knowledge and effect of the fatwa against the pharaonic cut ............................................2.

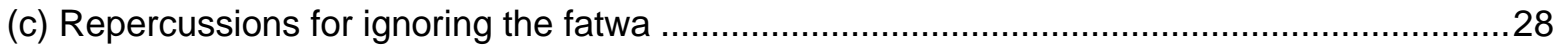

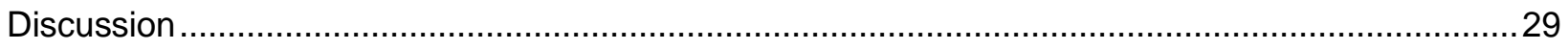

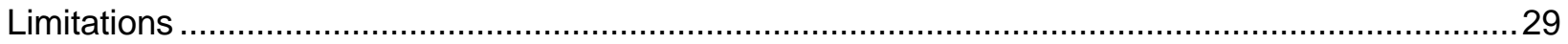

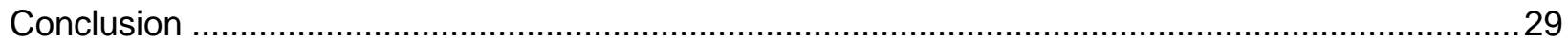

Implications for policy/programmes/research ........................................................................3

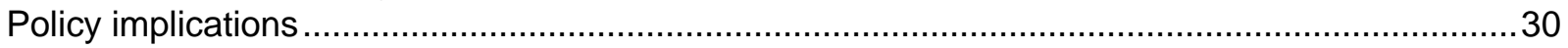

Programmatic implications ...............................................................................................

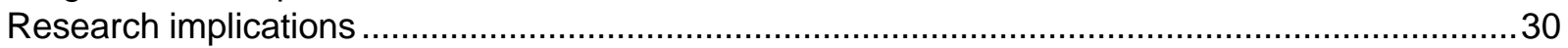

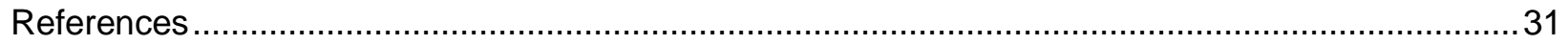

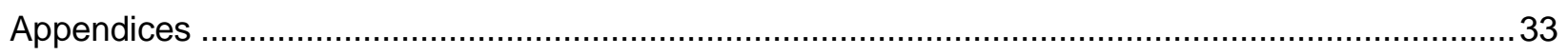




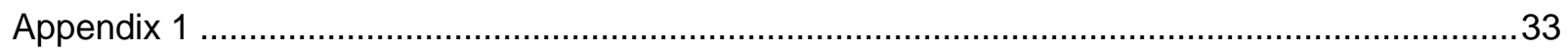

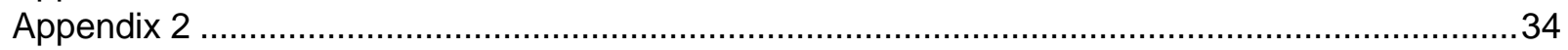

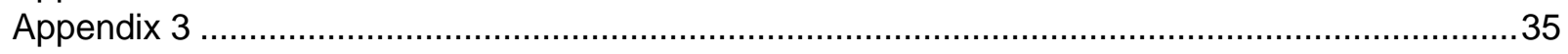

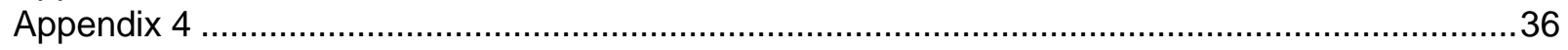




\section{List of Acronyms}

DfID Department for International Development

FGD Focus group discussion

FGM/C Female genital mutilation/cutting

MICS Multiple Indicator Cluster Survey

UNFPA United Nations Population Fund

UNICEF United Nations Children's Fund

WHO World Health Organization 


\section{Acknowledgments}

The authors thank the following people for their invaluable contributions to this study, especially those respondents who kindly participated in the community survey and group discussions and gave so openly of their attitudes and experiences, and the data collectors who worked diligently throughout the study.

We thank our colleagues at Population Council who provided support and insights as well as the editing and layout of this report.

Similar gratitude is expressed to the reviewers of the report: Drs. Michelle J. Hindin, Director of the Reproductive Health Program, Population Council; Susan M. Igras, Senior Technical Adviser, Institute for Reproductive Health, Georgetown University; and Ben Cislaghi, Assistant Professor in Social Norms, Gender Violence and Health Centre, London School of Hygiene and Tropical Medicine. 


\section{Executive Summary}

\section{Background}

More than 200 million girls and women alive today have undergone FGM/C across 30 countries in the Middle East, Asia, and Africa. While most affected countries have adopted legal frameworks prohibiting $\mathrm{FGM} / \mathrm{C}$, these have been varyingly effective in preventing the practice or significantly accelerating its abandonment. The success of programmatic interventions to address FGM/C has also been variable. One possible reason for the limited success of these initiatives is the neglect of the collectively held social norms underpinning the practice's continuation.

This study was conducted in Somaliland where FGM/C is almost universal among women aged 1549 years. It aimed to investigate: 1 ) if the norms associated with FGM/C are consistent with a social coordination norm; 2) which norms - if any-are associated with different stages of readiness to change; 3) how, to what extent, and by whom the norms and practices are being contested or altered' and 4) if the stages of readiness to change are associated with gender, location (i.e., rural and urban), and generational differences.

\section{Methods}

\section{Study design}

The study adopted a cross-sectional design, using mixed data-collection methods, i.e., household survey and focus group discussions (FGDs).

\section{Research setting \& study population}

The study was conducted in 30 villages in Somaliland, in five of its six regions: Awdal, Sahil, Maroodi-Jeex, Togdheer, Sanaag. and Sool. The study population comprised women aged 18-40 years who have given birth to at least one girl; approximately a quarter of the women's husbands also participated. A total of approximately 715 community members (570 women and 145 men for the survey) and eight FGDs were conducted.

\section{Recruitment process}

A multistage sampling procedure was employed to select a study sample. First, a cluster sample of districts was undertaken within the five study regions. Second, a random sampling of districts was conducted to select one study district in each region. Segmentation was undertaken within each site to randomly select one segment where the survey was conducted. In each selected district, villages were stratified by geographical location (rural and urban) to ensure a representative sample, with the numbers proportional to population size. As a result of security concerns, the research team had to change two of the selected study sites in which the survey was supposed to be undertaken in the region of Sanaag during the data-collection process. Randomization was therefore recomputed to select two new rural sites where data collection was subsequently undertaken.

Given that there could be more than one eligible woman in each household-who potentially shared characteristics, such as household wealth, household size, etc.-we selected only one eligible woman per household. To achieve this, the team approached each household and developed a comprehensive list of all women meeting the study inclusion criteria, from which we randomly selected one name. If this woman was unavailable or declined to participate in the survey, we randomly selected another woman from the same household list using a random number generator 
app called Random\#pro. One-quarter of the women's husbands were invited to participate, who were again randomly selected using the same app; no interviews were conducted as a marital pair.

Participants in the eight FGDs were selected using a purposive sampling technique-following identification of the original seed respondent with local social enablers in the community and healthcare facility settings-to construct the study sample. Using gender as a control characteristic, and two break characteristics-i.e., characteristics that differentiate groups from each other-of age (i.e., over 30 year of age vs. under 30 years of age) and location of residence (i.e., urban vs. rural), four focus group categories were defined: younger urban women/men, older urban women/men, younger rural women/men and older rural women/men. These participants were aged 18-40, unmarried or married, and the women had given birth to at least one girl.

\section{Data collection and analysis}

Following the tool development and piloting phases, the study's data-gathering activities included a household-level survey and FGDs. All data collection was conducted in the relevant local languages by trained research assistants and back-translated for analysis. Household survey data were analysed using descriptive statistics and factor analysis. FGDs were digitally audio recorded with the consent of all participants. Qualitative data were analysed by three independent analysts using a modified version of reflexive thematic analysis to identify patterned thematic meaning within the data using NVivo V11 software.

\section{Results}

Men completing the household survey were slightly older than the women, with higher educational levels, and proportionally more of married status. Among the FGD participants, men were proportionally more aged 20-29 years (mean age was identical), with much higher levels of education (especially at secondary, college/university), and more of an unmarried status. A much greater proportion of the women than men were from urban areas.

In the community survey, an inventory of 40 questions on explicit associations was administered to 715 respondents. To explore these data for the purpose of creating scales on explicit associations, we performed an exploratory factor analysis using Promax rotations (an oblique rotation) and principle axis factoring. The factor analysis based upon these explicit associations suggested a fourfactor solution: Factor 1 represents pro-medicalisation; Factor 2 represents being pro-Sunna but anti-pharaonic circumcision; Factor 3 represents feminine virtue; and Factor 4 represents anticircumcision (all forms). In measuring their internal consistency, the Cronbach's alpha values ranged from .835 (for feminine virtue) to .879 (for pro-medicalization), indicating high internal consistency across all four factors.

While additional advanced analysis will explore the concept of readiness to change, when directly asked regarding their readiness to continue the practice, as well as their commitment to, and preferred type of, cut for girls in their immediate family, there was a clear preference to continue the practice but only with the Sunna version $(85 \% ; n=612)$. Moreover, most respondents committed to circumcising the girls in their immediate family $(91 \% ; n=654)$, with the Sunna version of the cut again being the prime preference $(83 \% ; n=556)$. These quantitative findings were echoed by the qualitative data. 


\section{Discussion}

Despite the universality of FGM/C in Somaliland, there is clear variation in respondents' preferences for the practice in the future, with the vast majority endorsing the Sunna cut generally but also in terms of their commitment to undertake that form of circumcision with girls in their immediate family. Only $2 \%(n=14)$ advocated for the complete abandonment of the practice. It is also clear that norms are evolving-which are primarily religious and engendered in nature-that support these preferences, with a number of sanctions and rewards in place to ensure they are sustained.

\section{Implications for policy/programmes/research}

- Subject to the proposed further analyses, the study's initial policy implications include the need for further discussion on the type and limitations of normative readiness to change that can receive wider support within the Somaliland context and a debate on pragmatism and purism in policy initiatives.

- Programmatically, there is clearly a need to engage religious leaders, in part on the interpretation of religious texts and resulting pronouncements and unequivocal clarification of what the proposed Sunna exactly entails.

- A future research agenda based upon this study will be outlined following more conclusive additional analyses. 


\section{Introduction}

\section{Background}

Comprised of all procedures involving partial or total removal of the external female genitalia, or other injury to the female genital organs for nonmedical reasons (World Health Organization, 2016), female genital mutilation / cutting's (FGM/C) affects approximately 87 million girls and women aged 15 and older in the 28 countries where it is most common (Yoder, Wang, and Johansen 2013). More than 200 million girls and women alive today have undergone FGM/C across 30 countries in the Middle East, Asia and Africa (UNICEF 2016), with 70 million girls aged 0-14 years being, or are at risk of being, cut (Shell-Duncan, Naik, and Feldman-Jacobs 2017). Moreover, 15 of 29 countries show no clear evidence of a decline in prevalence (Shell-Duncan, Naik, and Feldman-Jacobs 2017).

While most affected countries have legally prohibited FGM/C, such measures have been varyingly effective in preventing the practice or accelerating its abandonment. The success of programmatic interventions to address $\mathrm{FGM} / \mathrm{C}$ has also been variable, with a review of their effectiveness in reducing its prevalence concluding not only were the effect sizes in reported studies relatively small, but the low quality of the body of evidence affected the interpretation of the results (Denison et al. 2009; Berg \& Denison 2012). Potential reasons for the ineffectiveness of legal prohibitions include sub-optimal enforcement of the prescriptive legislation, inadequate monitoring of the practice, and poor advocacy at the community level that could result in ignorance of the laws (Muthumbi et al. 2015). Another possible reason is the inadequacy of the theoretical paradigm framing FGM/C interventions neglecting the collectively held social norms underpinning the practice's continuation.

\section{Theoretical underpinnings}

Since its emergence, social norms theory has been used extensively to understand and improve a wide range of health-related behaviours (Rah et al. 2004; Campo et al. 2004; Scholly et al. 2005). Social norms are rules of behaviour that members of a community are expected and motivated to follow. They are held in place by the reciprocal expectations of people within a "reference group," and are maintained by social influence: approval, including positive sanctions, or disapproval, including negative sanctions; or by one's belief in the legitimacy of others' expectations among enough members of the reference group (i.e., in a coordinated manner).

In the last two decades, social norms theory has been particularly effective in investigating seemingly otherwise inexplicable compliance with FGM/C (UNICEF 2013). The theory contends that the perpetuation of harmful practices-such as FGM/C-and the creation of beneficial new ones, may be attributable to social motivations involving an entire community's interdependent beliefs and actions, rather than simply those of individuals and their families. Mackie et al. (2015) propose that there are three broad categories of beliefs: beliefs about the nonsocial environment; beliefs about the social environment, about what others in the group believe or do; and beliefs about one's self. While most development programs study and act upon beliefs about the nonsocial environment (e.g., beliefs about the effect of FGM/C on girls' bodies), few consider beliefs about the social environment, such as social norms. Social norms are beliefs about 1) what others do, and 2) what others think people should do, and often guide a person's actions in their social setting. If a harmful practice is social in nature, programmes that concentrate on the education of the individual, or an increase in the availability of alternatives, or provide external incentives, may be insufficient to modify social practices meaningfully. Rather, Mackie et al. (2015) contend that programmes may be 
more effective if they support the revision of social norms adhered to by people in the entire community.

Given that they can play a significant role in perpetuating a practice, social norms make it extremely problematic for individuals and families to stop a practice independently. FGM/C is therefore not only a social convention-i.e., a regularity widely observed by a group of agents—but also a coordinated social norm. Compliance is inevitable if the community is comprised of the individual's or family's significant others-i.e., their reference group-and it is motivated by expectations of rewards for adherence to the norm and fear of sanctions for non-adherence.

Importantly, for a beneficial new norm to come into existence, a sufficient number of group members must believe that enough of them are adopting the new norm (Mackie et al. 2015). This is a necessary prerequisite-and constitutes a "tipping point"' in the status quo-to effecting behavioral changes underpinned by societal norms, and often the culmination of a gradual process of normative reflection and transfiguration. More specifically, values deliberations about what one should do and what others should do can originate in a small core group, with knowledge shared, or diffused, especially from programmatic work-sometimes in an organized manner, with encouragement from practitioners but led by programme participants (Cislaghi et al. 2019) —-through the remainder of the reference group, until enough are ready to institute change.

\section{Prevalence of FGM/C in Somaliland}

In several countries contemporary and repeat data on FGM/C are limited, rendering conclusions from trend analysis problematic. Most recent Somalian data are derived from the 2006 UNICEF multiple indicator cluster survey (MICS) (UNICEF 2006) and its 2011 equivalent, which included a dedicated report on Somaliland (UNICEF Somalia and SMPND 2014). The near-universal prevalence of $\mathrm{FGM} / \mathrm{C}$ in 2006 renders differences by background variables minimal in percentage terms. However, there were zonal differences across the constituent areas of Somalia with, for example, the percentage of women undergoing infibulation varying: $77 \%$ nationally but $90 \%$ in the North West and North East zones, and $70 \%$ in the Central South zone. Similarly, while nationally two-thirds (65\%) believed that FGM/C should continue, in the North East zone 53\% supported its continuation and only $32 \%$ in the North West. Lastly, for the age at which girls experienced FGM/C, the majority (79\%) did so aged 5-9 years, while in the North West zone more girls $(21 \%)$ experienced $\mathrm{FGM} / \mathrm{C}$ at 8 years.

Five years later, in Somaliland, while there were differences between approval for $\mathrm{FGM} / \mathrm{C}(28.9 \%$ in Somaliland compared with $65 \%$ in Somalia as a whole in 2006) and the prevalence of FGM/C among daughters/girls (27.7\% in Somaliland compared with $46 \%$ in Somalia)—with the caveat that we cannot be sure if these data reflect true changes in support for continuation of $\mathrm{FGM} / \mathrm{C}$ or courtesy bias-there is also an interesting discordancy within Somaliland itself. Despite only $28.9 \%$ approving the practice, FGM/C was effectively universal (99.1\%) among women aged 15-49 years, with the majority experiencing the "pharaonic" FGM/C form (usually involving infibulation). Moreover, approval of the practice was not directly correlated with age (with older women approving it more). Those aged 15-19 years were more likely to want FGM/C to continue (45.3\%), with the range for those aged 20-9 years varying from $25.6 \%$ (25-29 year olds) to $32.7 \%$ (40-44 year olds).

Despite its near-universal status, however, there are signs of potential shifts in the type of FGM/C performed in Somaliland. Powell and Yussuf (2018) found a fundamental shift in the type of FGM/C procedures conducted-from the invasive pharaonic cut to the less severe Sunna cut, varyingly interpreted to entail a "pricking," "nicking," or excision of the prepuce of the clitoris-explained as an 
attempt to address the biomedical narrative of many anti-FGM/C campaigns (i.e., that the practice is deleterious to the girl's/woman's health) and find an acceptable balance between health preservation and sociocultural normative conformity. Combined with the discordancy in the 2006 national data regarding approval of the practice-nuanced by higher approval rates for its continuation among the youngest cohort interviewed-this layered landscape could potentially be explained by the "dimensions of readiness to change" typology described by Shell-Duncan, Naik, and FeldmanJacobs (2017) with the "chasm" between attitudinal disapproval and practice mitigated by the influence of societal factors, including socially coordinated normative values and people's reference groups (lbid: 25).

\section{Objectives}

The extent to which FGM/C is a socially coordinated norm has, however, been questioned. Efferson et al. (2015) postulate that if coordination is an appropriate theoretical framework explaining the practice, two predictions would hold: (i) communities should have either very low or very high cutting rates, with attitudes reflecting either a noncutting or a cutting norm, and (ii) if cutting practices and attitudes vary, pronounced discontinuity should separate noncutting from cutting communities. This study in Somaliland seeks in part to engage with the Efferson et al. (2015) predictions, investigating:

- If the norms associated with FGM/C are consistent with a social coordination norm;

- Which norms - if any-are associated with different stages of readiness to change;

- How, to what extent, and by whom the norms and practices are being contested or altered; and

- If the stages of readiness to change are associated with gender, location (rural and urban) and generational differences.

This study's goal is to generate evidence of the extent to which the norms associated with FGM/C are consistent with a social coordination norm, are associated with different stages of readiness to change, and the extent and nature of their contestation and associated socio-demographic variables.

The specific objectives of the study are to:

1) Enumerate potential shifts in social norms and behavior, including readiness to change, regarding $\mathrm{FGM} / \mathrm{C}$;

2) Determine what "readiness to change" exactly means, in terms of what is being changed and how that is manifesting itself;

3) Determine the extent to which FGM/C norms are supported as explicit associations, and consistently expressed by contrasting with more implicit associations; and

4) Measure positive and negative normative constructs associated with the dynamics of behaviour change.

Based upon these objectives, the study has several exploratory hypotheses:

1) Positive and negative norms associated with $\mathrm{FGM} / \mathrm{C}$ will be expressed consistently within the social coordination norm framework (i.e., presenting as a unimodal data distribution with minimal response discrepancies, given the practice's near universality).

2) Explicit associations among cut women will vary according to readiness to change but differences will be driven by valuations of positive associations rather than negative valuations.

3) Norms will be more contested by younger than older, female than male and urban- than ruralbased participants. 
4) Support for continuation of FGM/C will be lower among younger than older, female than male, urban- than rural-based participants.

5) Those who choose non-infibulating forms of FGM/C - such as the Sunna cut-in comparison with those who select infibulation for their daughters will have a lower readiness to change.

\section{Methods}

\section{Study design}

This is a cross-sectional, mixed methods study design.

\section{Study sites}

Located in the Horn of Africa, and bordered by Ethiopia to the west, Djibouti to the northwest, the Gulf of Aden to the north, the Indian Ocean to the east, and Kenya to the southwest, Somaliaofficially the Federal Republic of Somalia-has a population of around 10.8 million, of whom approximately $85 \%$ are ethnic Somalis (CIA 2016). The population is predominantly Muslim, the majority of whom are Sunni. Somalia is officially divided into eighteen regions (i.e., gobollada), in turn subdivided into districts. The regions are: Lower Juba, Middle Juba, Gedo, Bay, Bakool, Lower Shebelle, Banaadir, Middle Shebelle, Hiran, Galguduud, Mudug, Nugal, Bari, Sool, Sanaag, Togdheer, Woqooyi Galbeed, and Awdal. Northern Somalia is now de facto divided up among the autonomous regions of Puntland-self-declared as an autonomous but unrecognized state-and Somaliland, which is seeking international recognition as a sovereign state and is not governed by the Federal Government of Somalia. In central Somalia, Galmudug is another regional entity that emerged just south of Puntland. Jubaland in the far south is a fourth autonomous region within the federation (CIA 2016). In 2014, a new South West State was likewise established, and in April 2015 a formation conference was launched for a new Central Regions State (Anon. 2016).

Given wider security threats in the country, the study took place in Somaliland which, with the exception of low-intensity conflicts with neighboring Puntland over a border dispute in the Sanaag region, is relatively peaceful and stable. Its estimated population is 1.8 million. The study was conducted in 30 community settings in five of Somaliland's six regions: Awdal, Saahil, Maroodi-Jeex, Togdheer, and Sanaag.

\section{Participants}

Following the tool development and piloting phases-described below in the "Procedures" subsection-the study employed a mixed-methods approach, combining a household-level survey and vignette-based focus group discussions (FGDs).

The survey tool was applied within the community settings to women residents between the ages of 18-40 years who had given birth to at least one girl and one quarter of their husbands. The FGD guide was administered to eight FGDs among 64 people, including women who had given birth to a girl and men aged 18-40 who had a wife who had given birth to a girl.

\section{Procedures and Instruments}

The procedures followed and instruments used for the household survey and FGDs are outlined below.

(ii) Household-level survey 
The survey tool was developed in four stages: Stage 1: Using a mixed-methods study of dynamics of change in FGM/C in Senegambia (Shell-Duncan et al. 2010) as a guide, the tool was derived from a one-year qualitative study conducted in Somaliland in 2016-17, with explicit normative associations with FGM/C. Data were collected by male and female research assistants in Somaliland, using in-depth interviews (IDIs), key informant interviews (KIIs), and FGDs among men, women, religious leaders and various health-related professionals. Recorded interviews and group discussions underwent a multi-stage transcription-translation process to ensure data quality (for details, see Powell and Yussuf,2018,). The finalized English versions were thematically analyzed using template analysis (King 2012)-a pragmatic, iterative approach combining deductive and inductive analyses, producing a non-hierarchical coding framework, or "template"-with Nvivo version $11^{\circledR}$ (Bazeley 2007). Part of the analysis of these data identified perceptions regarding social norms -including its advantages and disadvantages - and changes in the practice. Overall, the qualitative data collection produced 24 FGDs among unmarried and married men and women, 20 KIls with key stakeholders, and 28 IDIs with healthcare workers and health-system administrators, entailing a total of 280 participants.

Stage 2: The resulting data were used to develop an ethnographically grounded household-level survey tool. While, for comparative purposes, the initial tool was based upon that used in Senegambia (Shell-Duncan et al. 2010) and retained key data domains (e.g., socio-demographic data), questions regarding FGM/C norms were informed solely by the Stage 1 qualitative findings. Specifically, data from the interviews and group discussions were analysed to identify normative positions regarding FGM/C. These positions were grouped into six overarching and 21 sub-themes (see Appendix 1), which could relate to either positive or negative associations with FGM/C dependent upon the perspective of the respondents expressing them. Examples of key positive thematic associations related to honouring cultural legacies, demonstrating sexual purity, and bodily cleanliness. Negative associations included the ostracization of uncut women, marital ineligibility, and peer pressure. These primary data were analysed to identify exemplar quotes from study participants that correlated with these positions, providing actual descriptions of people's normative tendencies. Based upon the resulting 142 exemplar quotes, and drawing upon language from these quotes, three researchers (RAP, MY, and $\mathrm{CK}$ ) developed 97 succinct normative statements, expressing both explicit positive and negative attitudinal dispositions to $F G M / C$ to ensure variability in questioning, to which a respondent could reply "agree" (equals 3 as an ordinal numerical value), "unsure" (equals 2), or "disagree" (equals 1). Following a review (by RAP, MY and CK) of these statements-to remove duplicates and clarify those with the potential for misinterpretation-they were subsequently reduced to 92; most (27) were grouped under the "Pressure to conform" theme, the fewest (7) under the "Abiding by social and religious hierarchies" theme (see Appendix 2).

The survey tool, as well as the FGD tool and informed consent forms, underwent a transcriptiontranslation process to ensure data quality. This entailed forward translation from English to the Somali language by two independent professionals conversant in their Somali mother tongue and English. Differences between these two translations were reviewed for any linguistic or cultural discrepancies and resolved by the two translators and the research coordinator, who was bilingual, to ensure their conceptual validity rather than literal translation. The tools and consent forms were back-translated into English by an independent translator whose mother tongue was Somali and who had an excellent command of English. Conceptual, cultural and phraseological differences between the original English documents and the back-translated version were reviewed and recorded in a translation reconciliation table. Listed discrepancies were again discussed with the 
research coordinator, with an emphasis on conceptual and cultural rather than linguistic equivalence, until a satisfactory translated version was agreed upon.

Stage 3: A three-part developmental pre-test of the survey was carried out in February 2019 for validity and cultural application: (a) Following the review of the explicit norm inventory, a conceptual review of the entire questionnaire was undertaken using cognitive interviews with six key Somaliland volunteer consultants (comprised of three female consultants [one from the Ministry of Education, another from the Ministry of Health gender section and one FGM/C focal person or the community member] , and three male consultants [a project officer, a project director/manager, and a researcher with FGM/C experience]).

Cognitive interviews were conducted to ensure the tool was fit for the purpose, ensuring respondents would be able to understand the questions asked, would understand them in the same way, and that they would be willing and able to answer them (Collins 2003). The consultants were briefed in detail about the study and invited to offer their feedback and insights to help develop an effective and culturally appropriate list of statements. The consultants had experience of at least five years in either tool development or FGM/C. Questions were administered in Somali to the consultants and followed by simple interviews to assess their comprehension of the translated questions (including terminological appropriateness of descriptions used to discuss FGM/C), as well as any suggestions they had regarding their alternate phrasing, especially with more sensitive topics.

Data from these interviews were collected by comments written on the questionnaire by the research assistants and by taking notes on the oral debriefing about the survey questions. These first interviews clarified which questions were easier or more difficult to understand, providing insights for further adjustments before their administration in Stage 2. Consequently, any questions that were unclear or worded poorly were either adjusted or removed, leaving only those that operated best in the field. Politically sensitive questions the study team were advised to omit were: (i) the cut status of co-wives and (ii) the explicit designation of clan and sub-clan, with the latter seen as highly problematic. Identifying variation by clan was seen as divisive and could threaten the viability of the survey. Consequently, we used geographic location as proxies for clan and sub-clan but remained cognisant of the sensitivities regarding the subject and the fact that geographical location and clan/sub-clan are not necessarily directly correlated.

(b) We assessed the influence of flow, naturalness, question order, and reliability using a test-retest approach. The tool was administered in individual interviews with seven women (aged 18-40 who havd given birth to at least one girl) and three men to assess appropriateness of skip patterns, respondent fatigue, and conceptual understanding.

(c) The revised version of the tool was administered to the same groups as in Stage 2 but with 30 women and 10 men. The tool was then applied within the community settings to 570 women and 145 men/husbands (one quarter), using a sample size formula adapted from that used by UNICEF Somalia and Somaliland Ministry of Planning and National Development based on the Somaliland Multiple Indicator Cluster Survey:

$$
n=D \times \frac{Z^{2}{ }_{1-\alpha / 2} P(1-P)}{d^{2}}
$$


Where:

$D \quad$ Design effect, set at 1.5 , to account for homogeneity among respondents sampled from the same village

$P \quad$ Estimated proportion of women 15-49 years who approve of FGM/C (set at $28.9 \%$ based on the 2011 estimates for Somaliland)

$Z_{1-\alpha-2} \quad Z$-score corresponding to the probability with which it is desired to be able to conclude that the observed proportion does not occur by chance $(Z=1.96$ for two-tailed test at $95 \%$ confidence level)

$d^{2} \quad$ Degree of accuracy or precision, set at $\pm 5 \%$.

A multistage sampling procedure was employed to select a study sample. First, a cluster sample of districts was undertaken within the five study regions. Second, a random sampling of districts was conducted to select one study district in each region (Appendix 3). Segmentation was undertaken within each site to randomly select one segment where the survey was conducted (Appendix 3). In each selected district, villages were stratified by geographical location (i.e., rural and urban) to ensure respondents were representative of the target population in both areas, with the numbers proportional to population size. As a result of security concerns, the research team had to change two of the selected study sites in which the survey was supposed to be undertaken in the region of Sanaag during the data-collection process. Randomization was therefore recomputed to select two new rural sites where data collection was subsequently undertaken.

In terms of identifying eligible women (and their husbands) for the study, given there could be more than one in each household-who potentially shared characteristics, such as household wealth, household size, etc.-we selected only one eligible woman per household. To achieve this, and with the assistance of social enablers among the target populations, female participants were identified by research assistants through a comprehensive household listing of all female residents between the ages of 18-40 years who had given birth to at least one girl, from which we randomly selected one name. If this woman was unavailable or declined to participate in the survey, we randomly selected another woman from the same household list using a random number generator app called Random\#pro. We also retained records of the number of respondents who declined to participate so we could report the nonresponse rate, which was zero (i.e., nobody declined to participate). The resulting sample was comprised of 143 people in each district-72 in urban and 71 in rural areas (Appendices 3 and 4). For one quarter of the selected women $(n=570)$, their co-resident husband was also interviewed $(n=145)$.

\section{(ii) Focus group discussions}

To address the potential limitations of explicit associations, this study also used vignette-based FGDs that employed more implicit, association-based theoretical scenarios to reveal narratives around community-level FGM/C normative contestation and change, values deliberations, the factors promoting these deliberations and readiness to change. Whilst not replicating the implicit association test-a measure used in social psychology to detect the strength of a person's immediate automatic associations with social constructs communicated through pertinent computer screen images, as employed in Sudan by Efferson et al. (2015)_the normative-based vignettes, exploring community attitudes and preferences, similarly allow researchers to detect individual differences in associations that cannot necessarily be easily measured through explicit, self-reported methods due to lack of awareness, reactivity, or social desirability bias (Krumpal, 2013). The 
vignettes require a number of relatively rapid judgments that are thought to reveal cognitive processes over which respondents do not have conscious awareness, thereby avoiding the types of response bias that can arguably influence explicit, survey-based measures (e.g., lack of awareness, reactivity, or social desirability bias). They not only create the opportunity for respondents to articulate their thoughts on hypothetical, community-based scenarios-minimising the explicit test measure biases outlined above-but also afford participants the cognitive space and time to reflect thoroughly upon the multiple considerations that may impact upon each scenario. The focus group guide employed three vignette scenarios:

- The main characters, Bilan and her mother Faduma, were presented as a typical daughter and mother from the village where the FGD was held. Bilan was soon to undergo FGM but, unlike her other two daughters, Faduma wanted Bilan to undergo a less severe cut (i.e., Sunna not pharaonic). Participants were then asked about what others would think of her decision; the most important people she would consult with, including her husband, and the advice they would give her; and any rewards or sanctions that might be involved.

- Caasho is a typical 10-year-old girl from the village. One day Caasho's mother and father decide that it is best for their daughter to be cut in one month's time but they want it to be undertaken by a health professional rather than a traditional cutter. Participants were then asked about the preference to use a health professional, what her aunts and uncles would think about the parents, the grandmother's preference for a traditional cutter, and the thoughts of her friend on the decision.

- $\quad$ The last vignette concerned Warsame, a married man from the village who heard on the radio that there was a fatwa from a religious council that said that all girls had to have a Sunna cut. Participants were then asked about what his wife would think of the fatwa, their preference that none of their young daughters be cut and abandoning the practice altogether, and the response of family and friends to the latter decision.

Following a review of the vignette-based FGD guide investigating marriage in Cameroon (Cislaghi unpublished), and development of the above questions with expert input from Cislaghi on social norms exploration, the FGD guide was administered to eight women aged 18-40 years who had given birth to at least one girl, and eight men, in FGDs to assess the social acceptability and cultural validity of the vignette scenarios. The guide explored descriptive norms, injunctive norms, noncompliance of the main character of the vignette, sanctions, sensitivity to sanctions and exceptions (Cislaghi \& Heise 2017). Participants were administered the guide and asked to verbalize their thought processes following each vignette.

The revised guide was administered to eight FGDs (four each in two regions, Maroodi-Jeex and Toogdheer, with three rural-two of which were with men-and five urban settings—-three of which were with women) with 64 people, among women who had given birth to a girl and men who had a wife who had given birth to a girl, aged 18-40. With regard to the composition of the FGDs, using gender as a control characteristic and two break characteristics-characteristics that differentiate groups from each other (Knodel 1993)—of age (over 30 year of age vs. under 30 years of age) and location of residence (urban vs. rural), four focus group categories were defined: younger urban women $/$ men, older urban women/men, younger rural women $/$ men and older rural women $/ \mathrm{men}$. These participants were aged 18-40, unmarried or married, and had given birth to at least one girl.

To compile the actual study sample, community sensitization was undertaken by the Ministry of Health $(\mathrm{MoH})$ and the Ministry of Employment, Social Affairs and Family (MESAF) focal persons and 
community social workers. Using a purposive sampling technique-following identification of the original seed respondent with local social enablers in the community and healthcare facility settings - to construct the study sample, the FGDs were conducted in the relevant local languages by trained research assistants (matched by gender) and digitally audio recorded. The FGDs were undertaken using a moderator and observer, with each group held at a location acceptable to the participants. A self-complete participant record was provided to all FGD participants to gather demographic data,.

\section{Data analysis}

For the household survey, all interviewers used tablets to collect the data. For all completed interviews, each research assistant wrote the final outcome for all household visited and interviews conducted on the Interviewer Progress Sheet. This enabled the team leaders and field coordinator to track data collection progress and address any issues arising. It was the responsibility of the interviewer to review each questionnaire when they finished the interview to ensure all questions were answered. The resulting completed survey questionnaires were reviewed for completeness by the field manager. The team leaders also conducted shadow interviews and spot checks in selected households to ensure fieldworkers were interviewing the correct households and eligible respondents, as well as asking questions, and recording the answers correctly. The interviewers and team leaders met on a daily basis to hold regular reflection meetings to review interviewers' progress. They discussed fieldwork issues, data quality, and the performance and assignment of work each interviewer had completed by filling in a daily progress sheet. The field coordinator monitored the day-to-day field activities, as well as the performance and quality of work completed by the field team, and reported on a daily basis to the research coordinator by completing the supervisor's daily monitoring sheet.

Each interviewer uploaded their data at the end of each day to a password-protected laptop in the Population Council (PC) office in Nairobi, with the research coordinator reviewing the data to determine distributions, and identify any data entry errors and anomalous outliers, and cleaning the data for analysis using SPSS. The analysis was descriptive and inferential in nature, the former to profile the study population and the latter to address the study hypotheses and questions.

For the FGDs, digital audio recordings of the group discussions underwent a multi-stage transcription-translation process to ensure data quality:

- $\quad$ Recordings were transcribed verbatim by experienced Somali-speaking transcribers;

- These anonymized transcripts were forward-translated from Somali to English by SomaliEnglish speaking translators;

- All transcripts were back-translated by additional independent English-Somali speaking translators; and

- Differences between the originally translated and back-translated English versions were identified and documented, and anomalies discussed between the translators, until a consensus on an accurate translation was achieved. All identifying information was then removed.

Data analyses for this study—both quantitative and qualitative-are ongoing. Consequently, this section outlines what analysis has been completed and what further analysis is proposed.

\section{Household survey}

(a) Descriptive analysis 
Socio-demographic data was analysed using basic descriptive statistics (i.e., frequencies) and tests of association (e.g., chi-square and appropriate measures of central tendency determined by the data distribution) were also used to explore differences in the study population metrics by respondent gender.

(b) Inferential analysis

\section{Completed undertaken: factor analysis}

An exploratory factor analysis was performed-with rotations as needed-to see how explicit associations cluster and to select items to create as scales that will underpin additional data analyses. Internal consistency was calculated using Cronbach's alpha; according to Nunnally (1967), in initial stages of research, reliabilities of $0.5-0.6$ are sufficient.

In the full survey, an inventory of 40 questions on explicit associations was administered to 715 respondents. Each statement, derived from illustrative quotes from themes discovered in the qualitative segment of the research, was followed by a response choice: agree, disagree or not sure. To explore these data for the purpose of creating scales on explicit associations, we performed a factor analysis using Promax rotations (an oblique rotation) and principle axis factoring, retaining factors with an eigenvalue greater than one and comprised of more than one item.

Analyses to be completed

Proposed analyses to be undertaken include:

- Extent to which FGM/C-related norms are associated with different types and stages of readiness to change

A first step will be an exploratory determination of what "readiness to change" means in Somaliland (in terms of what is being changed and how that is manifesting itself; e.g., abandonment of the practice, or changing its type, the age at which it is being undertaken, or its medicalisation.),

Given the near-universality of FGM/C, participants were asked to self-identify with one of a number of categories of readiness to change that entailed more than simply their adherence to, or readiness to abandon, the practice per se. This analysis will entail comparing a staging algorithm based on responses to multiple questions, and creating a scale to assign readiness to change stage, be that in the severity of the cut, abandonment, or medicalisation. This will be compared to the self-described "stage" question.

Logistical regression analysis will be employed to identify any correlations between explicit positive and negative responses to the FGM/C valuation survey items and the different types and stages of readiness to change. This will be undertaken to determine whether the driving forces underpinning readiness to change are driven by positive associations rather than negative ones (e.g., perceptions of adverse health risk) and the extent to which FGM/C norms are supported as explicit associations and consistently expressed in contrast with more implicit associations.

Moreover, and modeled on the work of Wander, Moreau, and Shell-Duncan (under review), additional proposed analyses entail the following:

- Extent to which FGM/C-related norms are associated with socio-demographic variables and the extent to which, and the nature of how and by whom, FGM/C-related norms are contested 
Logistical regression analysis will be employed to identify any key socio-demographic variables correlated to positive and negative responses to the FGM/C valuation survey items and the actual/probability of future cut status of daughters.

In this way, a determination will also be made using multiple logistic regression of the extent to which the $\mathrm{FGM} / \mathrm{C}$ status of a mother and youngest daughter/foster daughter is correlated with readinessto-change categories. Other variables to be explored will include medicalisation using limited indicators (e.g., person who performed the cut, location of cut, and pain-relieving medications used) and the extent to which those choosing non-infibulating forms of FGM/C-such as the Sunna cut-in comparison with those who select infibulation for their daughters will have a different readiness to change.

Additional correlates to be analysed include younger and older, female and male, and urban- and rural-based participant variables, with a determination of the extent to which support for continuation of $\mathrm{FGM} / \mathrm{C}$ varies by each, or any patterning regarding how its norms are contested.

\section{- Extent to which FGM/C-related norms are consistent with a social coordination norm}

Analysis will explore the extent to which, despite the near universality of its practice, any variations in positive and negative norms associated with FGM/C are expressed consistently within the social coordination norm framework (i.e., presenting as a distinct normative schema in a bimodal data distribution).

A further aspect of this analysis will be a determination of the extent to which the way in which FGM/C is practiced (actual or intended behaviour) has a "modifier effect" on individual attitudes, or preferences for ideal behavior. More specifically, it will identify the extent to which the way FGM/C is undertaken might influence individual FGM/C preferences (i.e., modifies them). For example, does having undergone a medicalised form of the cut render a person more likely to prefer that FGM/C continue or be discontinued?

\section{Focus group discussions}

Following transcription and translation, and deductively informed by social norms theory and the parameters of each vignette narrative, three independent analysts (to address potential bias) used a modified version of reflexive thematic analysis (Clark et al., 2019) to identify patterned thematic meaning within the data, whilst being inductively receptive to thematic content arising from the data irrespective of their synergy with traditional understanding of social norms.

The modified analysis process entailed a largely sequential six phases which, however, was also recursive in nature, with movement back and forth between the different phases to facilitate a rigorous process of data interrogation and engagement: (i) Familiarisation with the data: this involved reading and re-reading the data, immersing the analysts in its content; (ii) Coding: this involved the three analysts and PI reviewing the same single script to identify some initial main and sub-themes under each vignette, as well as noting how many times they arose, generating coding labels for each vignette. Script 2 was then reviewed, using this initial coding frame, to determine if the codes were evident again and then refined the coding frame to incorporate new themes and sub-themes, highlighting new codes. The relevant study team members held a series of meetings to determine any misplaced assumptions in their coding and discuss the coding labels to identify provisional recurring themes and patterns of interpretation.

(iii) Generating initial themes: this involved examining the codes and collated data to identify significant patterns of meaning (i.e., potential themes), as well as collating data relevant to each potential theme to assess its viability. The team then independently reviewed and refined these 
themes. (iv) Reviewing themes: this involved the team checking the potential themes against the dataset to determine if they reflected a convincing set of narratives for each of this study's three vignettes, and if they answer the research question. This phase also entailed a refinement of the themes, including their splitting, combining, and discarding, driven primarily by the search for patterns of shared meaning underpinned by a central concept or idea. (v) Defining and naming themes: this phase involved a detailed analysis of each theme, working out its scope and focus, and determining what is behind each; (vi) Quantifying the frequency and importance of thematic and subthematic social norms: this phase entailed ranking and tabulating the frequency of reporting of the norms-descriptive (what a person thinks others do), injunctive (what a person thinks other will approve/disapprove of someone doing), and subjective (what a person thinks significant others expect someone to do). The sanctions reported to enforce them-through social approval (e.g., status) or disapproval (e.g., isolation, other sanctions) via expected and acceptable behaviours, attitudes, and aspirations, both positive and negative in nature-were then listed. Recurrent thematic concepts around each norm were compared to determine their importance as influencing factors, the social group advocating them, and colour code-highlighting the negative norms that needed to be addressed or transformed and the positive norms that needed to be promoted as beneficial ones. (vii) Writing up: this phase involved merging together the analytic narrative and extracted data and contextualising the analysis within both the study's quantitative household survey data and existing literature.

Examples of the themes and their codes will be provided in the final technical report. Following further proposed analyses, the qualitative data derived from the study will integrated into the additional quantitative data analyses that is proposed.

\section{Ethical considerations}

Risks to participants included a potential breach of confidentiality and potentially sensitive questions on the practice of FGM/C. Written informed consent was obtained from all participants before conducting the interviews. Additionally, counseling services were made available for anyone who might become distressed. To negate any adverse responses from their community, no FGD participants were named and participants were asked to commit to nondisclosure of the discussion content during the informed consent process. The study was reviewed and approved by the Population Council (reference number 834; dated 31 January 2018) and the Somaliland Ministry of Employment, Social Affairs and Family (no reference number or approval date).

\section{Results}

This section first presents the socio-demographic profile of the household survey and FGD participants, the factor analysis, and preferences regarding the future versions of the practice that were undertaken. These are a necessary prerequisite to more advanced data analysis, that is outlined below as a path forward, and the qualitative findings.

\section{Respondents' socio-demographic profiles}

As Table 1 shows, men completing the household survey were slightly older than the women (especially those aged 40 years and above), with higher educational levels (especially at secondary, college/university), with proportionally more of married status. Among the FGD participants, men were proportionally more aged 20-29 years (mean age was identical), with much higher levels of 
education (especially at secondary, college/university), and more of an unmarried status. A much greater proportion of the women than men were from urban areas.

Table 1. Socio-demographic characteristics of participants

\begin{tabular}{|c|c|c|c|c|c|c|c|c|}
\hline \multirow[t]{3}{*}{$\begin{array}{l}\text { Socio-demographic } \\
\text { profile }\end{array}$} & \multicolumn{4}{|c|}{$\begin{array}{c}\text { HH survey } \\
(n=715)\end{array}$} & \multicolumn{4}{|c|}{$\begin{array}{l}\text { FGDs } \\
(n=64)\end{array}$} \\
\hline & \multicolumn{2}{|c|}{ Male } & \multicolumn{2}{|c|}{ Female } & \multicolumn{2}{|c|}{ Male } & \multicolumn{2}{|c|}{ Female } \\
\hline & $\bar{n}$ & $\%$ & $\bar{n}$ & $\%$ & $\mathbf{N}$ & $\%$ & $\mathbf{n}$ & $\%$ \\
\hline Gender & 145 & 100 & 570 & 100 & 32 & 100 & 32 & 100 \\
\hline \multicolumn{9}{|l|}{ Age } \\
\hline Mean age & \multicolumn{2}{|c|}{34} & \multicolumn{2}{|c|}{32} & \multicolumn{2}{|c|}{30} & \multicolumn{2}{|c|}{30} \\
\hline $18-19$ years & 0 & 0 & 23 & 4 & 0 & 0 & 3 & 9 \\
\hline 20-29 years & 35 & 24 & 191 & 33 & 16 & 50 & 12 & 38 \\
\hline 30-39 years & 60 & 41 & 267 & 47 & 13 & 41 & 13 & 41 \\
\hline 40 years & 50 & 35 & 89 & 16 & 3 & 9 & 4 & 12 \\
\hline \multicolumn{9}{|l|}{ Education level } \\
\hline No formal education & 58 & 40 & 401 & 70 & 6 & 19 & 17 & 53 \\
\hline Primary & 37 & 26 & 125 & 22 & 4 & 12 & 11 & 34 \\
\hline Secondary & 25 & 17 & 27 & 5 & 5 & 16 & 4 & 13 \\
\hline College/university & 25 & 17 & 17 & 3 & 17 & 53 & 0 & 0 \\
\hline \multicolumn{9}{|l|}{ Marital status } \\
\hline Married & 145 & 100 & 497 & 87 & 18 & 56 & 28 & 88 \\
\hline Unmarried & 0 & 0 & 0 & 0 & 14 & 44 & 4 & 12 \\
\hline Widowed & 0 & 0 & 33 & 6 & 0 & 0 & 0 & 0 \\
\hline Divorced & 0 & 0 & 40 & 7 & 0 & 0 & 0 & 0 \\
\hline \multicolumn{9}{|l|}{ Location } \\
\hline Urban & 74 & 51 & 285 & 50 & 16 & 50 & 24 & 75 \\
\hline Rural & 71 & 49 & 285 & 50 & 16 & 50 & 8 & 25 \\
\hline \multicolumn{9}{|l|}{ Religion } \\
\hline Islam & 145 & 100 & 570 & 100 & 32 & 100 & 32 & 100 \\
\hline
\end{tabular}

\section{Factor analysis}

In the full survey, an inventory of 40 questions on explicit associations-not always norms; sometimes beliefs-was administered to 715 respondents. Each statement, derived from illustrative quotes from themes discovered in the qualitative segment of the research, was followed by a response choice: agree, disagree or not sure. To explore these data for the purpose of creating scales on explicit associations, we performed a factor analysis using Promax rotations (an oblique rotation) and principle axis factoring. We retained factors with an eigenvalue greater than one and comprised of more than one item. Results were confirmed by visually examining the scree plots. The factor analysis based upon these explicit associations suggested a four-factor solution. The loadings are shown in Table 2 as follows:

Table 2. Four-factor analysis study loadings 


\begin{tabular}{|c|c|c|c|c|}
\hline & Factor 1 & Factor 2 & Factor 3 & Factor 4 \\
\hline 476 Circumcision performed by a health professional is safe & .782 & & & \\
\hline $\begin{array}{l}477 \text { Being circumcised in a hospital is safer than circumcision } \\
\text { done at home }\end{array}$ & .822 & & & \\
\hline $\begin{array}{l}478 \text { Community members should seek the services of health } \\
\text { workers to perform circumcision }\end{array}$ & .893 & & & \\
\hline 479 Health professionals encourage less severe circumcision & .633 & & & \\
\hline $\begin{array}{l}483 \text { Circumcision performed by health professionals } \\
\text { encourages the continuation of the practice }\end{array}$ & .508 & & & \\
\hline $\begin{array}{l}486 \text { I trust health professionals who perform female } \\
\text { circumcision }\end{array}$ & .844 & & & \\
\hline $\begin{array}{l}427 \text { Families whose daughters have Sunna circumcision } \\
\text { deserve good reputations }\end{array}$ & & .526 & & \\
\hline 435 a Sunna circumcision is required by the community & & .522 & & \\
\hline 446 There should be a law to ban pharaonic circumcision only & & .505 & & \\
\hline 456 Pharaonic circumcision causes health problems & & .829 & & \\
\hline 459 Sunna circumcision is less harmful than the pharaonic cut & & .648 & & \\
\hline 460 Pharaonic circumcision can cause infection & & .857 & & \\
\hline 461 Pharaonic circumcision can lead to death & & .606 & & \\
\hline $\begin{array}{l}462 \text { Pharaonic circumcision can cause complications with } \\
\text { childbirth }\end{array}$ & & .861 & & \\
\hline $\begin{array}{l}455 \mathrm{~A} \text { girl should be able to pray when she is circumcised } \\
\text { (either Sunna or pharaonic) }\end{array}$ & & & .618 & \\
\hline $\begin{array}{l}\text { 455b A girl who has been circumcised (either Sunna or } \\
\text { pharaonic) is pure and clean }\end{array}$ & & & .742 & \\
\hline $\begin{array}{l}463 \text { Only a woman with some form of circumcision (Sunna or } \\
\text { pharaonic) can become a mature woman }\end{array}$ & & & .569 & \\
\hline $\begin{array}{l}465 \mathrm{~A} \text { girl who is circumcised is more beautiful than an } \\
\text { uncircumcised girl }\end{array}$ & & & .795 & \\
\hline $\begin{array}{l}466 \text { If a woman is not circumcised, the private part of her body } \\
\text { will look ugly }\end{array}$ & & & .778 & \\
\hline 474 Circumcision makes girls moral & & & .574 & \\
\hline 462b Sunna circumcision can cause diseases & & & & .687 \\
\hline 462c Sunna circumcision can lead to death & & & & .912 \\
\hline $\begin{array}{l}\text { 462d Sunna circumcision can cause complications with } \\
\text { childbirth }\end{array}$ & & & & .867 \\
\hline
\end{tabular}

The Kaiser-Meyer-Okin measure of sampling adequacy is a measure that can vary between 0 and 1 , with a value closer to 1 considered better, indicating correlations are compact and factor analysis is appropriate. Our measure is .866, which is considered very good. Bartlett's test of sphericity tests the null hypothesis that the correlation matrix is an identity matrix, where all diagonal elements are 1 , and off-diagonal elements are 0 . For our data, this hypothesis was rejected at $p<.01$.

An important but sometimes neglected element of factor analysis is the need to interpret the results. We suggest that Factor 1 represents pro-medicalisation, Factor 2 represents being pro-Sunna but 
anti-pharaonic circumcision, Factor 3 represents feminine virtue, and Factor 4 represents anticircumcision (all forms). Before creating scales, we assessed the reliability by computing Cronbach's alpha, a measure of internal consistency. The values ranged from .835 (for feminine virtue) to .879 (for pro-medicalization), indicating high internal consistency across all four factors rather than item redundancy, given the relatively small number of items.

\section{Readiness to change}

While additional advanced analysis (e.g., correlates and predictors) will explore the concept of readiness to change, when directly asked regarding their readiness to continue the practice, as well as their commitment to, and preferred type of, cut for girls in their immediate family, there was a clear preference to continue the practice but only with the Sunna version (85\%; $n=612$ ) (Table 3).

\section{Table 3: Continuation/discontinuation of FGM/C types}

\begin{tabular}{|l|c|c|}
\hline Continuation/discontinuation of FGM/C & $\mathbf{n}$ & $\%$ \\
\hline All form of circumcision to continue & 16 & 2 \\
\hline Only pharaonic circumcision to continue & 68 & 10 \\
\hline Only Sunna circumcision to continue & 612 & 85 \\
\hline All forms of female circumcision should stop & 14 & 2 \\
\hline Unsure what should continue or not. & 5 & 1 \\
\hline Total & 715 & 100 \\
\hline
\end{tabular}

Moreover, most respondents committed to circumcising the girls in their immediate family $(91 \%$; $n=654)$, with the Sunna version of the cut again being the prime preference $(83 \% ; n=556)$ (Table 4):

Table 4: Future and type circumcision of girls in immediate family

\begin{tabular}{|l|c|c|}
\hline Future circumcision & $\mathbf{n}$ & $\%$ \\
\hline Yes & 654 & 91 \\
\hline No & 48 & 7 \\
\hline Unsure & 13 & 2 \\
\hline Total & 715 & 100 \\
\hline Type of circumcision & & 11 \\
\hline Pharaonic & 73 & 83 \\
\hline Sunna & 556 & 6 \\
\hline Unsure & 38 & 100 \\
\hline Total & 667 & \\
\hline
\end{tabular}

\section{Qualitative findings}

In analyzing the FGDs and their theoretical vignettes, this section focuses on the reporting of descriptive and injunctive norms and any associated rewards or sanctions regarding their maintenance or contestation (see Table 5 for a summary of the findings). 
Table 5: Summary of normative findings from FGDs

\begin{tabular}{|c|c|c|c|c|c|c|c|c|}
\hline $\begin{array}{c}\text { Norms } \\
\#\end{array}$ & $\begin{array}{l}\text { Behavior } \\
\text { under } \\
\text { normative } \\
\text { influence }\end{array}$ & $\begin{array}{l}\text { Population } \\
\text { complying }\end{array}$ & $\begin{array}{l}\text { Reference } \\
\text { groups }\end{array}$ & Themes \& sub-themes & $\begin{array}{l}\text { Descriptive } \\
\text { norms }\end{array}$ & Injunctive norms & Sanctions & Rewards \\
\hline \multirow{6}{*}{1} & $\begin{array}{l}\text { Undergoing } \\
\text { Sunna cut to } \\
\text { minimise } \\
\text { harm }\end{array}$ & $\begin{array}{l}\text { Mothers / } \\
\text { parents }\end{array}$ & & $\begin{array}{l}\text { (a) Knowledge of different cut types } \\
\text { - Circumcision = purification } \\
\text { - Sunna, pharaonic \& 2-stich pharaonic }\end{array}$ & & & & \\
\hline & & & & $\begin{array}{l}\text { (b) Preferred type of cut } \\
\text { - Sunna; no stitching just picking } \\
\text { - Less harmful \& fewer / no complications }\end{array}$ & & $\begin{array}{l}\text { Rejection of } \\
\text { choice }\end{array}$ & & $\begin{array}{l}\text { Supported by } \\
\text { religious } \\
\text { teachings }\end{array}$ \\
\hline & & & $\begin{array}{l}\text { Fathers/ } \\
\text { relatives }\end{array}$ & $\begin{array}{l}\text { (c) Transition between cut types } \\
\text { - Definition of Sunna cut }\end{array}$ & $\begin{array}{l}\text { In a state of } \\
\text { flux }\end{array}$ & $\begin{array}{l}\text { Not approved = } \\
\text { not } \\
\text { circumcision/parti } \\
\text { al circumcision }\end{array}$ & & \\
\hline & & & Family & $\begin{array}{l}\text { (d) Generational differences in Sunna } \\
\text { attitudes } \\
\text { - Supported by younger generation } \\
\text { - More aware of pharaonic complications } \\
\text { - Supported by women who've undergone } \\
\text { pharaonic cut } \\
\text { - But not universally the case }\end{array}$ & & $\begin{array}{l}\text { Sunna cut is not } \\
\text { circumcision \& } \\
\text { such cut girls are } \\
\text { immoral }\end{array}$ & & \\
\hline & & & & $\begin{array}{l}\text { (e) Religious support of Sunna } \\
\text { - Advocated for as seen as having no } \\
\text { complications } \\
\text { - Influencing support among key reference } \\
\text { groups }\end{array}$ & $\begin{array}{l}\text { Permissible } \\
\text { under Islamic } \\
\text { religion } \\
\text { Shaping } \\
\text { endorsement } \\
\text { of the Sunna } \\
\text { cut }\end{array}$ & & & \\
\hline & & & & $\begin{array}{l}\text { (f) Gender \& decision-making } \\
\text { - Mother key decisionmaker in "kitchen } \\
\text { issues" } \\
\text { - Grandmothers are important but not all } \\
\text { powerful } \\
\text { - Can be informed after preferred cut } \\
\text { done } \\
\text { - Decision-making is kept secret } \\
\text { - Convinced of decision by health \& } \\
\text { religious arguments } \\
\text { - Men not informed of issues "between } \\
\text { women's legs" }\end{array}$ & & & & \\
\hline
\end{tabular}




\begin{tabular}{|c|c|c|c|c|c|c|c|}
\hline \multirow{2}{*}{2} & $\begin{array}{l}\text { Being cut by a } \\
\text { health } \\
\text { professional } \\
\text { to minimise } \\
\text { harm }\end{array}$ & $\begin{array}{l}\text { Mothers/ } \\
\text { parents }\end{array}$ & $\begin{array}{l}\text { (a) Decision-making \& medicalisation } \\
\text { - Using a health professional } \\
\text { - Parents are ultimate decisionmakers } \\
\text { - Grandmothers exert significant influence } \\
\text { - Opinion can be followed in respect } \\
\text { - Can be convinced of decision } \\
\text { - Other family members/friends = little } \\
\text { power }\end{array}$ & $\begin{array}{l}\text { Not } \\
\text { widespread so } \\
\text { sometimes } \\
\text { secretly done }\end{array}$ & & & \\
\hline & & & $\begin{array}{l}\text { (b) Religion \& medicalisation } \\
\text { - Religious leaders play a key role } \\
\text { - Can be disagreed with in rural areas } \\
\text { - Less awareness }\end{array}$ & $\begin{array}{l}\text { Most don't } \\
\text { object to } \\
\text { medicalised } \\
\text { cut } \\
\text { Traditionally } \\
\text { prefer a } \\
\text { pharaonic cut }\end{array}$ & $\begin{array}{l}\text { Included in } \\
\text { Mosque Friday } \\
\text { sermons } \\
\text { Follow what } \\
\text { leaders } \\
\text { recommend }\end{array}$ & & $\begin{array}{l}\text { Seen as good } \\
\text { for girl's } \\
\text { health }\end{array}$ \\
\hline & $\begin{array}{l}\text { Following } \\
\text { religious } \\
\text { guidance to } \\
\text { be a good } \\
\text { Muslim }\end{array}$ & $\begin{array}{l}\text { All } \\
\text { community }\end{array}$ & $\begin{array}{l}\text { (a) Religious leaders support change } \\
\text { - Abandonment of the practice not } \\
\text { supported } \\
\text { - Abandonment possible only if supported } \\
\text { by religion }\end{array}$ & $\begin{array}{l}\text { Abandonment } \\
\text { is not common }\end{array}$ & $\begin{array}{l}\text { Being cut is } \\
\text { "obligatory" }\end{array}$ & & \\
\hline 3 & & & $\begin{array}{l}\text { (b) Knowledge \& effect of the fatwa against } \\
\text { the pharaonic cut } \\
\text { - People will continue with Sunna cut } \\
\text { - Abandonment not possible religiously } \\
\text { - Continuing with pharaonic cut possible if } \\
\text { it is seen as traditional } \\
\text { - Repercussions of ignoring the fatwa } \\
\text { - Abandonment as transgression } \\
\text { - Generational differences in support of } \\
\text { abandonment }\end{array}$ & & $\begin{array}{l}\text { Adherence to } \\
\text { religious decrees } \\
\& \text { what they } \\
\text { promote. } \\
\text { Commanded by } \\
\text { religious leaders } \\
\text { to stop practicing } \\
\text { pharaonic cut } \\
\text { Need to form a } \\
\text { new norm against } \\
\text { the pharaonic cut }\end{array}$ & $\begin{array}{l}\text { Depicted as } \\
\text { "abandoning" the culture } \\
\text { Treated as an "outsider" } \\
\text { Seen as "against the } \\
\text { culture \& religion" or as } \\
\text { "devils" } \\
\text { Ridiculed in society by } \\
\text { gossip } \\
\text { Marriageability may be } \\
\text { jeopardised }\end{array}$ & $\begin{array}{l}\text { Younger } \\
\text { people see } \\
\text { abandonment } \\
\text { as more } \\
\text { "right" }\end{array}$ \\
\hline
\end{tabular}




\section{Norm 1: Undergoing Sunna cut to minimise harms}

\section{(a) Knowledge of different types of cut}

In general terms, the term circumcision-or purification-was reported as referring to $F G M / C$ regardless of the cut type. Most participants reported there being two main types of $\mathrm{FGM} / \mathrm{C}$-Sunna and pharaonic. A man and a woman, for instance, said respectively:

"They use the words Sunna and pharaonic to refer to it. The people of the past practiced pharaonic (fircooni) while the present people practice Sunna."

Abaarso, Rural men under 30 yrs

"The types are pharaonic and Sunna but when girls are circumcised, we use purification but the type of circumcision is not specified."

Qoyta, Rural women under 30 yrs

Others instead revealed that there are three types: pharaonic, Sunna, and a third that entails two stitches that is similar to the pharaonic - with most people currently practicing the Sunna type:

"There are three types of circumcision. One with complete stitching called pharaonic. One with two stitches that is similar to pharaonic and a third in which the girl is pricked only and nothing else is done. So, the Sunna is the last one"

Qoyta, Rural women under 30 yrs

\section{(b) Preferred type of cut}

Most participants thought Sunna was the least harmful form of FGM/C, since it involved pricking, no stitching and had fewer or no complications when compared to the pharaonic cut. Sunna was reported to be widely practiced-especially in the urban areas-unlike the pharaonic, which was said to have been increasingly abandoned because of its negative health complications but remains in more rural areas. A new descriptive norm, the Sunna was also reported to be approved by the Islamic religion, acting as a religious norm:

"Yes, but I don't think the Sunna circumcision is used. The Sunna is less severe, and it is not a bit complicated like the old traditional practice, so girls suffer fewer problems. Yes, because it involves pricking to bleed the clitoris... No stitching is done on the girl when Sunna circumcision is done."

Abaarso, Rural men under 30 yrs

"We understand Sunna circumcision very well because it is pricking only. What we understand about the Sunna circumcision is that the religion allows it." The religion that has allowed the Sunna circumcision by doing pricking of the girl. ... The religion has instructed us to do the Sunna circumcision and it involves pricking of girls."

Hargeisa, Urban women under 30 yrs

"Currently, I believe the most common form is the Sunna circumcision which has no stitching but has pricking of the frontal tip of the clitoris." ... In the same way, I think it involves the girl being circumcised by doing pricking of the clitoral hood. I think the Sunna type which the religion permits is practiced in this district and it involves doing pricking on the girl."

Qoyta, Rural men 30 yrs and over

\section{(c) Transition between cut types and definitions}

Participants explained that, in each community, the most common form of FGM/C is frequently also 
sustained by injunctive norms. Some communities, however, experienced a phase of transition, with confusion about what the leading injunctive norm might be. A woman, for instance, explained that people were unsure of what form to practice:

"[Community members] ... are divided into two: those supporting the Sunna and those who want the pharaonic. Then when you want to do the Sunna, the father or the relatives may disagree with you... If you try do the Sunna, many people will reject it and will tell you the pharaonic is better than the Sunna. So, you will get confused on which type to choose."

Hargeisa, Urban women under 30 years

Knowing what form of FGM/C one person went through, however, is difficult. One cannot distinguish girls who have gone through Sunna and those who have gone through the pharaonic cuts.

Confusion also exists on what the Sunna cut actually is, with a few participants stating that the Sunna is considered partial circumcision or no circumcision at all, hence some do not approve of it, suggesting that a descriptive norm is in a state of flux, influenced partly by its increasing popularity but also by confusion regarding what it exactly is. Other participants mentioned that the Sunna type of $\mathrm{FGM} / \mathrm{C}$ entailed cutting of a small part of the clitoris and/or having two stitches as opposed to the pharaonic, where complete stitching is undertaken. Another participant mentioned that Sunna involves cutting the whole clitoris while others mentioned that it entails pricking only:

"No. When circumcision is heard we believe it is the former type so there is no confusion and the two types are clear. Circumcision (pharaonic) involves stitching and the Sunna is a girl who is not touched (not circumcised at all) or only pricked."

Hargeisa, Urban men 30 yrs and over

"I understand Sunna circumcision as one involving the female genitals. The female genitalia has a small piece called the clitoris which is usually removed. Then nothing else is done such as stitching. So, the word used is pricking or Sunna."

Hargeisa, Urban men under 30 yrs

\section{(d) Generational differences in attitudes toward Sunna}

The Sunna cut was generally supported by the younger generation, in part because they had greater awareness of FGM/C and the complications resulting from the severe pharaonic cut. Moreover, women who underwent the pharaonic cut have first-hand experience of its health complications and are most likely to support the Sunna cut among their daughters and granddaughters. However, this is not always the case. Some maternal and paternal grandparents who underwent the pharaonic type of FGM/C, and older aunts and elderly neighbours, are likely to oppose the choice of the Sunna cut. It was also noted that these groups are likely to oppose the Sunna cut if they have not received information on the complications of the pharaonic cut:

"If it is a grandparent they will tell her to do pharaonic circumcision. ... Both maternal and paternal grandmothers will tell her to do pharaonic circumcision on her daughter.... Bilan's grandparents will tell her to let her daughter undergo the previous form of female circumcision which was pharaonic. Maternal and paternal grandparents' of Bilan will say say, "let the girl undergo the circumcision we knew and understood (pharaonic)."'

Hargeisa, Urban men under 30 yrs 
Participants also reported that people from the older generation-especially women-prefer the pharaonic type of cut because they believe that those undergoing the lesser cut are left "open" and, as such, are not circumcised and are immoral.

"She will refuse her grandchild to get Sunna and will say, 'Do pharaonic on her because the old parents never liked an open girl but liked a closed (stitched) one."”

Hargeisa, Urban women 30 yrs and over

"Her sister will tell her, 'We never had any problems with pharaonic. So, circumcise your daughter because infibulation will prevent her from being immoral."'

Burco, Urban women 30 yrs and over

"She will tell her, 'The reason why these girls are immoral is because they were not circumcised.' She will advise her to do pharaonic on the girl."

Burco, Urban women 30 yrs and over

There is minimal indication-as discussed in the third vignette-that this awareness has resulted in the emergence of a new norm: the total abandonment of the practice.

\section{(e) Religious support for Sunna}

Participants also reported that religious leaders support the Sunna cut since they believe it is permissible under the Islamic religion. The religious leaders also advocate for it since it is seen as having no complications, contributing to injunctive norms that have persuaded multiple reference groups (e.g., father, aunts, uncles, and neighbors) to support and undergo the "lesser" cut because of its religious endorsement.

"If she tells the nurse she wants to circumcise her daughter, the nurse might advise her to move on to a more modern and acceptable form, which is the Sunna. The religious leaders will say do the Sunna because it's a religious requirement. ... Mostly, it's the religious leaders and health professional only who advice people to do Sunna circumcision. So they will tell her to do Sunna."

Hargeisa, Urban men under 30 yrs

"The father will advise her to do the Sunna on the girl because the Sunna is currently practiced.... The maternal aunt will advise the girl to undergo the Sunna because the religion allows it.... The father will agree with the Sunna because the father doesn't want his daughter to have complications ... so the father is a parent and will not wish bad for his daughter and will advise her to do the Sunna....Men and women are not the same. Men prefer the Sunna because pharaonic brings health complications...The father is a parent who doesn't want bad things to happen to his children and wants the Sunna for them which is less severe. So he might agree to practice it and his advice will be the Sunna...The young ones and the guys who know something about the religion support it. An educated person supports it. A majority of the people who support it are the young ones who have knowledge and have listened to the awareness creation. So a majority support the Sunna...I think Sunna circumcision is the only one that the people support now. People have full knowledge about the complications of pharaonic and the Sunna is a mercy from Allah sent to us."

Hargeisa, Urban women 30 yrs and over

The preferred type of cut also varied by rural versus urban populations; those who had been educated about the practice, and those who were less informed of the health complications of the severe cut, which is also more expensive to perform, and the fact that girls in the community can get married even after undergoing the lesser done in the community, so there are no sanctions around marriageability prospects, at least for the Sunna cut. 
"There are three reasons why Faduma preferred the Sunna. The cost of performing circumcision is huge. When infibulation is done on the girl, the cost is 250,000/300,000 Somaliland shillings $(\$ 25 / \$ 30)$, the cost for the Sunna may be 150,000 Somaliland shillings (\$15). The second reason is the complications she experienced which she used to hide. The other reason is, previously when a girl is to get married, if she is open (not circumcised), she will not be married and if the marriage happens, she will be brought back to you which will be shameful. So, she realized that the culture is no longer there."

Burco, Urban women 30 yrs and over

The role of the religious norm was consistently expressed as a critical consideration, with one participant stating that people will be "forced" to follow what has been religiously prescribed:

"I'm a father. I will agree with Fadumo if she was my wife because it is practicing the religion."

Qoyta, Rural Men 30 yrs and over

"When she consults with the religious scholars, Fadumo's husband will be forced to accept what the religion permitted to be done."

Qoyta, Rural Men 30 yrs and over

"Her husband will tell her that the religion did not mention the pharaonic to be done so do Sunna and let her go."

Qoyta, Rural women under 30 yrs

\section{(f) Gender and decisionmaking: the mother's power}

Many participants reported that a mother might consult her husband but any disagreement he may have with her decision may not change it; he may also just be informed in a de facto manner, after the cut is already performed. Whilst the opinion of grandmothers are important, parents or mothers alone who prefer the Sunna cut may keep their decision on the cut type a secret or instead attempt to convince the grandmother of their decision using health-related arguments and citing religious doctrinal support.

"If the father sees the girl being circumcised or circumcised, he will agree with her decision because the household work is separate. If it is a matter of women, women have a say on it but if the issue is conflict, men are responsible for resolving the differences."

Hargeisa, Urban men 30 yrs and over

"Traditionally, men are not told about women's activities because this is part of the kitchen issues. Similarly, what happens between a woman's legs, men are not informed."

Hargeisa, Urban men 30 yrs and over

\section{Norm 2: Being cut by a health professional to minimise harm}

\section{(a) Decision-making and medicalization}

Despite not being a prevalent descriptive norm, most participants felt that the vignette where the parents of young Caasho plan to have her cut using a health professional does happen-sometimes in secrecy-but others could not relate to this form of cut:

"Yes, it can happen but currently people take their daughters to health professionals secretly to do circumcision."

Hargeisa, Urban men 30 yrs and over 
"It is possible this story happens because some people have their girls get circumcised by a health professional."

Hargeisa, Urban women 30 yrs and over

"It can happen this way because some of the girls are being circumcised in a health facility."

Qoyta, Rural women under 30 yrs

While parents are seen as the ultimate decisionmakers in the practice of FGM/C, in the Somali community grandmothers exert a significant influence on the decision-making process, unlike aunts and uncles, neighbours, and friends. Consequently, while grandmothers will not impose their preference for choice of cut on their children, their views are taken into consideration with considerable work undertaken to convince them to agree to a medicalized form of the practice:

"She will listen to her parents' advice because they will be held accountable if a problem arises, but the friends can do nothing."

Hargeisa, Urban women under 30 years

"Once the family has agreed to take their girl to a health facility to circumcise her, the aunts and uncles will agree with that decision."

Hargeisa, Urban men 30 yrs and over

"She will listen to her family's advice because they are the ones to have the final decision."

Hargeisa, Urban women under 30 years

Consequently, parents might change their decision to take their children to a health professional for circumcision if a grandmother disagrees with it-partly out of respect-but they may also change their decision if everyone else disagrees with it:

"If the grandmother disagrees with that decision, the parent must revoke their decision because in every house, the grandparents rule."

Burco, Urban women 30 yrs and over

"If the grandmother gets involved in the matter, I believe that the little girl would not be taken to a health professional to do the circumcision."

Hargeisa, Urban men 30 yrs and over

"Out of the respect for the parent [grandmother], they might circumcise the young girl using the traditional method."

Hargeisa, Urban women 30 yrs and over

"Yes, if all members of the family are on the same side and against her and are opposed to the decision of having a health professional perform the circumcision, she may be satisfied and change her decision."

Qoyta, Rural men 30 yrs and over

\section{(b) Religion and medicalisation}

Religious leaders again play a key role in decisions made in the community, including FGM/C. Parents tend to make decisions that mirror what the religious leaders recommend. Consequently, the majority of people in the community will not object to medicalised circumcision.

"They [aunts] will agree with their decision because the religious scholars have recommended health professionals to do it." 
Hargeisa, Urban men under 30 yrs

"Parents ... will tell the grandmother that the religious leaders support the practice of Sunna and will inform her that they instructed people to let a health professional perform the circumcision, so that the grandmother understands the decision of the parents."

Hargeisa, Urban men 30 yrs and over

"People have now gained awareness. Mosques do awareness on it and it is included in the Friday sermons by the religious leaders. Circumcision by health professional is good for the girl's health."

Qoyta, Rural men 30 year and over

These religious and gender norms are overlayed by the issue of rurality/urbanicity, with people from urban centers are more receptive to alternative thinking-including from educational campaignsand more likely to allow their daughters to be circumcised by health professional, in contrast to those from more rural settings who prefer the traditional pharaonic cut:

"Maybe if they (aunts and uncles) live in a city, they will support their decision as they have received awareness creation. If they are from the rural settings, they will be against that decision, but it is best for a health professional to do it when you look at the health aspect because it's safer."

Hargeisa, Urban men under 30 yrs

"They will support that decision if they live in a city, if they are in the rural area, they will disagree with that decision."

Hargeisa, Urban Men 30 yrs and over

\section{Norm 3: Being a good Muslim}

\section{(a) Religious leaders supporting change}

The vignette which concerned the married man, Warsame, who heard that there was a fatwa from a religious council stating that all girls had to have a Sunna cut but who then decided, with his wife, to abandon the practice altogether, was not a common scenario. However it was hypothetically possible, including using religious arguments on what is considered "obligatory":

"It may happen and may continue with some of the religious scholars saying this is correct and that the Sunna can be abandoned."

Qoyta, Rural men 30 yrs and over

"This story is something that can happen if the Sunna is supported but if left out, it can't happen."

Qoyta, Rural women under 30 yrs

"It could happen because the Sunna can be abandoned religiously because it is not obligatory but anything obligatory cannot be abandoned."

Hargeisa, Urban men under 30 yrs

However, a majority of the participants felt that total abandonment was unrealistic given that the practice-especially the Sunna form-is supported by culture and religion. Indeed, to some participants abandonment was unimaginable and shameful:

"It is common but may not occur because the Sunna cannot be abandoned."

Hargeisa, Urban men 30 yrs and over 
"This way of saying to leave the girls uncircumcised, we never heard about it. Is this true? We never heard it in the religion and never saw anyone saying leave the girls uncircumcised."

Hargeisa, Urban women 30 yrs and over

"Yes it can happen if the religious leaders say all forms of circumcision should be abandoned. If not, it can't happen."

Hargeisa, Urban women under 30 yrs

"They will bring great shame to their children and their families if they abandon all forms of circumcision."

Burco, Urban women 30 yrs and over

\section{(b) Knowledge and effect of the fatwa against the pharaonic cut}

Religious leaders provide direction around FGM/C through their decrees, and community members are expected to adhere to the decrees. Consequently, most people in the community follow what religious leaders promote and continue with Sunna circumcision rather than abandonment, seeking clarification from these leaders where there is confusion or uncertainty:

"Warsame and his wife will accept the fatwa as the correct one because religious leaders have commanded people to do the Sunna and to stop practicing the pharaonic."

Burco, Urban women 30 yrs and over

"People will say a new project has come up. Controversies will eventually rise. So people will go back to the religious leaders to clarify why that family took the decision to abandoned Sunna circumcision."

Burco, Urban women 30 yrs and over

"Religious leaders have proposed the practice of Sunna circumcision as clarified by the religion. People will take the fatwa and practice it."

Qoyta, Rural men 30 yrs and over

"Once they have listened, it is something clear which our religion clarified. When they hear the religious leaders releasing lectures through the radios, they will see Sunna circumcision as a clear step forward which has its basis on the Hadiths."

Qoyta, Rural women under 30 yrs

"Yes they will follow it because they are religious people and they will not oppose the religious leaders."

Qoyta, Rural women under 30 yrs

"Since Warsame's family is not a nonreligious family, they will follow the fatwa and practice it."

Qoyta, Rural women under 30 yrs

While some participants thought that it may be possible for the family to reject the fatwa if they believed in the pharaonic type of circumcision, others could take time being convinced by it and would need to be educated on it and its implications at the mosques:

"I think they will not agree to follow it because it happens that some people listen to the radio and hear it but they might still continue with their traditional practice."

Hargeisa, Urban women 30 yrs and over

"It is possible that they might not follow and practice the fatwa because they believe in the old tradition."

Hargeisa, Urban women 30 yrs and over 
"They will not follow it because it is the first time the religious scholars produced it. So if it's not emphasized again and again, it may be difficult for the people to follow the fatwa if it's not addressed in the mosques regularly."

Hargeisa, Urban men under 30 yrs

\section{(c) Repercussions for ignoring the fatwa}

Ignoring the Fatwa would result in sanctions, however, with those people considered to be either wrong or nonbelievers, with pressure placed upon them to follow the religious instruction:

"They will be seen to be wrong and they will be advised to change their decision. It is good to do what the religion permits. For that reason, they will change their decision."

Hargeisa, Urban women under 30 yrs

"We will be isolated from the neighborhood. I will feel depressed because the girl is uncircumcised."

Burco, Urban women 30 yrs and over

"Someone who is an antisocial person. After that you will be vulnerable to the community in which you live and then you will withdraw your decision."

Hargeisa, Urban men under 30 yrs

"People will see them as mad people because they neglected what the religion has instructed."

Hargeisa, Urban women 30 yrs and over

Most participants felt that total abandonment of FGM/C transgresses local culture and religion and the person who doesn't circumcise their daughter will also be considered rebellious by the larger community and ostracised:

"I have abandoned my culture and I have left the Sunna which my religion recommended. So I would have felt someone who is an outsider."

Abaarso, Rural men under 30 yrs

"They will be seen as people who are against the culture and religion."

Burco, Urban women 30 yrs and over

"May GOD not make us Warsame and his wife. We are people who follow the religion of Islam. We say, 'GOD, make us understand it.' May GOD keep the thoughts of Warsame and his wife away from us. Maybe they are devils."

Qoyta, Rural men 30 yrs and over

"If I was Warsame or his wife, I would become a symbol of ridicule that people talked about whenever I stood within community."

Qoyta, Rural women under 30 yrs

"If I were Warsame or his wife, I will feel my girls would not get married."

Qoyta, Rural women under 30 yrs

"I will not find a safe place to hide if I do that."

Qoyta, Rural women under 30 yrs

However, it was reported that the younger generation is receptive to total abandonment, which is seen by some as the way forward for circumcision:

"If they are from the old generation, people will wonder about them but if they are from these young people, they will be seen to be right and their decision will be agreed with. I 
heard a woman saying she was cut using heaven's razor so she should be left like that and don't do anything else to the girls."

Hargeisa, Urban women 30 yrs and over

"I and Warsame have made a clear decision and will never change it whatever the cost." Qoyta, Rural women under 30 yrs

\section{Discussion}

This report only outlines the quantitative findings in terms of the socio-demographic profile of the study participants-both for the household survey and the FGDs; the factor analysis and preferences regarding the future versions of the practice that was undertaken as a necessary prerequisite to more advanced data analysis, outlined below as a path forward; and qualitative findings.

An important finding, however, is that despite the universality of FGM/C in Somaliland, there is clear variation in respondents' preferences for the practice in the future, with the vast majority endorsing the Sunna cut generally but also in terms of their commitment to undertaking that form of circumcision with girls in their immediate family. Only $2 \%(n=14)$ advocated for the complete abandonment of the practice. Further proposed analysis will explore the correlates and predictors of such preferences (e.g., younger and older generation, rural and urban, and male and female differences).

It is also clear that norms-which are primarily religious and engendered in nature-are evolving in support of these preferences, with a number of sanctions and rewards in place to ensure that they are sustained, which will be explored in further analysis.

\section{Limitations}

This report only provides descriptive quantitative findings from the study and therefore is only a partial picture of FGM/C currently in Somaliland. This limitation will be addressed subsequently when more rounded and integrated analysis will be written up.

\section{Conclusion}

Given the amount and richness of emerging quantitative and qualitative data generated by this study, and the need to integrate both when all analyses are completed, additional analyses to be undertaken include:

- Developing scales to assign readiness to change;

- Analysing the survey items on "readiness to change" so there is a better understanding of what that concept entails in the Somaliland context;

- Determining how these explicit associations vary by self-described readiness to change;

- Further analysis of the qualitative data to develop a coherent narrative using both data types;

- Analysing the extent to which FGM/C-related norms are associated with socio-demographic variables and the extent to which, and the nature of how and by whom, FGM/C-related norms are contested;

- Determining the extent to which FGM/C-related norms are consistent with a social coordination norm; and 
- Exploring the extent to which the way FGM/C is practiced (actual or intended behaviour) has a "modifier effect" on individual attitudes, or preferences for ideal behaviour.

\section{Implications for policy/programmes/research}

Policy implications: Subject to the proposed further analyses, the study's initial policy implications include the need for further discussion on the type and limitations of normative readiness to change that can receive wider support within the Somaliland context and a debate on pragmatism and purism in policy initiatives.

Programmatic implications: Programmatically, there is clearly a need to engage religious leaders, in part on the interpretation of religious texts and resulting pronouncements and unequivocal clarification of what the proposed Sunna exactly entails.

Research implications: A future research agenda based upon this study will be outlined following the more conclusive additional analyses. 


\section{References}

Anon. 2016. "Adado conference kicks off in central Somalia." Retrieved from: www.garoweonline.com/en/news/somalia/adado-conference-kicks-off-in-central-somalia

Bazeley, P. 2007. Qualitative Data Analysis with NVivo (2nd edition). London: SAGE Publications Ltd.

Berg, R.C. and E. Denison. 2012. "Effectiveness of interventions designed to prevent female genital mutilation/cutting: A systematic review," Studies in Family Planning 43(2): 135-146. https://doi 10.1111/j.1728-4465.2012.00311.x

Campo, S., K.A. Cameron, D. Brossard, and M.S. Frazer. 2004. "Social norms and expectancy violation theories: Assessing the effectiveness of health communication campaigns," Communication Monographs 71(4): 488-470.

Central Intelligence Agency (CIA). 2016. The World Factbook: Somalia. Retrieved from: www.cia.gov/library/publications/the-world-factbook/geos/so.html

Cislaghi, B., Denny, E.K., M. Cissé, P. Gueye, B. Shrestha, P.N. Shrestha, G. Ferguson, C. Hughes, and C.J. Clark. 2019. "Changing social norms: The importance of 'organized diffusion' for scaling up community health promotion and women empowerment interventions," Prevention Science 20(6): 936-946.

Cislaghi, B. and L. Heise. Under review. "Four avenues of normative influence." 2017. STRIVE Technical Brief: Measuring Social Norms. London: London School of Hygiene and Tropical Medicine.

Clarke, V., V. Braun, G. Terry, and N. Hayfield. 2019. "Thematic analysis." In Handbook of Research Methods in Health and Social Sciences, P. Liamputtong (ed.), 843-860. Singapore: Springer.

Collins., D. 2003. "Pretesting survey instruments: An overview of cognitive methods," Quality of Life Research 12(3): 229-238. https://doi 10.1023/a:1023254226592

Denison, E., R.C. Berg, S. Lewin, and A. Fretheim. 2009. Effectiveness of interventions designed to reduce the prevalence of female genital mutilation/cutting. Report from Kunnskapssenteret No. 25-2009. Oslo: Nasjonalt kunnskapssenter for helsetjenesten.

Efferson, C., S. Vogt, A. Elhadi, H.E.F. Ahmed, and E. Fehr. 2015. "Female genital cutting is not a social coordination norm," Science 349(6255): 1446-1447. https://doi: 10.1126/science.aaa7978

King, N. 2012. "Doing template analysis." In Qualitative Organizational Research, G. Symon and C. Cassell (eds.), 426-450. London: Sage.

Knodel, J. 1993. "The design and analysis of focus group studies: A practical approach." In Focus groups: Advancing the State of the Art, D.L. Morgan (ed.), 35-50. Newbury Park, CA: Sage Publications.

Krumpal, I. 2013. "Determinants of social desirability bias in sensitive surveys: A literature review," Quality and Quantity 47(4): 2025-2047. https://doi.org/10.1007/s11135-011-9640-9

Mackie, G., F. Moneti, H. Shakya, and E. Denny. 2015. What Are Social Norms?: How Are They Measured? Geneva and San Diego: UNICEF and University of California, San Diego, Center on Global Justice 
Muthumbi, J., J. Svanemyr, E. Scolaro, M. Temmerman, and L. Say. 2015. "Female genital mutilation: A literature review of the current status of legislation and policies in 27 African countries and Yemen," African Journal of Reproductive Health 19(3): 32-40.

Nunnally, J.C. 1967. Psychometric Theory. New York: McGraw-Hill.

Powell, R.A. and M. Yussuf. 2018. Changes in FGM/C in Somaliland: Medical narrative driving shift in types of cutting. Working Paper. New York: Population Council

Rah, J., C. M. Hasler, J.E. Painter, and K.M. Chapman-Novakofski. 2004. "Applying the theory of planned behaviour to women's behavioural attitudes on consumption of soy products," Journal of Nutritional Education and Behaviour 36(5): 238-244. https:// doi 10.1016/s1499-4046(06)60386-2

Scholly, K., A.R. Katz, J. Gasgoine, and P.S. Holck. 2005. "Using social norms theory to explain perceptions and sexual health behaviours of undergraduate college students: An exploratory study," Journal of American College Health 53(4): 159-166. https://doi 10.3200/JACH.53.4.159166

Shell-Duncan, B., Y. Hernlund, K. Wander, and A. Moreau. 2010. Contingency and change in the practice of female genital cutting: dynamics of decision making in Senegambia. Summary Report. Available at: http://csde. washington. edu/bsd

Shell-Duncan, B., R. Naik, and C. Feldman-Jacobs. 2017. A State-of-Art Synthesis of Female Genital Mutilation/Cutting: What Do We Know? New York: Population Council

United Nations Children's Fund (UNICEF). 2016. Female Genital Mutilation/Cutting: A Global Concern. New York: UNICEF . 2013. Female Genital Mutilation/Cutting: A statistical Overview and Exploration of the Dynamics of Change. New York: UNICEF.

. 2006. Somalia Multiple Indicator Cluster Survey, 2006: Monitoring the Situation of Children and Women. Somalia: UNICEF

UNICEF Somalia and Somaliland Ministry of Planning and National Development (SMPND). 2014. Somaliland Multiple Indicator Cluster Survey, 2011, Final Report. Nairobi: UNICEF Somalia and SMPND.

Wander, K., A. Moreau, and B. Shell-Duncan. Under review. "Evidence from Senegambia that female genital cutting is upheld by a social coordination norm."

World Health Organization (WHO). 2016. WHO Guidelines on the Management of Health Complications from Female Genital Mutilation. Geneva: WHO.

Yoder. P.S., S. Wang, and E. Johansen. 2013. "Estimates of female genital mutilation/cutting in 27 African countries and Yemen," Studies in Family Planning 44(2): 189-204. https://doi 10.1111/j.1728-4465.2013.00352.x. 


\section{Appendices}

\section{Appendix 1}

Table 1.1: Summary of overarching and sub-themes arising from qualitative data on explicit norms

\begin{tabular}{|c|c|c|}
\hline & Overarching theme & Sub-themes \\
\hline \multirow{6}{*}{1} & \multirow{6}{*}{ Pressure to conform } & Ostracization of uncut women \\
\hline & & Generational peer pressure \\
\hline & & Isolation of uncut girl's family/parents \\
\hline & & Marital ineligibility \\
\hline & & Proper parenting \\
\hline & & Community expectations \\
\hline & & \\
\hline \multirow{4}{*}{2} & \multirow{4}{*}{ Obeying tradition, culture and legal edicts } & Honoring tradition \\
\hline & & Modern motherhood \\
\hline & & Meeting cultural expectations \\
\hline & & Following legal obligations \\
\hline \multirow[b]{2}{*}{3} & \multirow[b]{2}{*}{ Abiding by social and religious hierarchies } & Obeving narental authority \\
\hline & & $\begin{array}{l}\text { Obeying parental authority } \\
\text { Following religious requirements }\end{array}$ \\
\hline \multirow{2}{*}{4} & \multirow{2}{*}{ Health and hygiene } & Cleanliness of the body \\
\hline & & Associated health risks \& benefits \\
\hline \multirow{3}{*}{5} & \multirow{3}{*}{ Sexuality and womanhood } & Passage into womanhood \\
\hline & & Chaste sexual reputation \\
\hline & & Moral virtuousness/purity \\
\hline \multirow{4}{*}{6} & & Medicalisation \\
\hline & \multirow{3}{*}{ Acceptability of practice changes } & Cut severity \\
\hline & & Decreased age \\
\hline & & Abandonment \\
\hline
\end{tabular}




\section{Appendix 2}

Table 2.1: Summary of overarching and sub-themes arising from qualitative data on explicit norms and three-stage statements

\begin{tabular}{|c|c|c|c|c|c|}
\hline & Overarching theme & Sub-themes & $\begin{array}{l}\text { \# original } \\
\text { statements }\end{array}$ & $\begin{array}{l}\text { \#1 revised } \\
\text { statements }\end{array}$ & $\begin{array}{l}\text { \#2 revised } \\
\text { statements }\end{array}$ \\
\hline \multirow{6}{*}{1} & \multirow{6}{*}{ Pressure to conform } & Ostracization of uncut women & 6 & 5 & 5 \\
\hline & & Generational peer pressure & 4 & 3 & 3 \\
\hline & & $\begin{array}{l}\text { Isolation of uncut girl's } \\
\text { family/parents }\end{array}$ & 8 & 6 & 6 \\
\hline & & Marital ineligibility & 3 & 4 & 4 \\
\hline & & Proper parenting & 8 & 8 & 7 \\
\hline & & Community expectations & 2 & 2 & 2 \\
\hline & \multicolumn{2}{|l|}{ Total } & 31 & 28 & 27 \\
\hline \multirow{4}{*}{2} & \multirow{4}{*}{$\begin{array}{l}\text { Obeying tradition, } \\
\text { culture, and legal edicts }\end{array}$} & Honouring tradition & 2 & 2 & 2 \\
\hline & & Modern motherhood & 1 & 2 & 2 \\
\hline & & Meeting cultural expectations & 1 & 4 & 4 \\
\hline & & Following legal obligations & 1 & 2 & 3 \\
\hline & \multicolumn{2}{|l|}{ Total } & 5 & 10 & 11 \\
\hline \multirow{3}{*}{3} & \multirow{2}{*}{$\begin{array}{l}\text { Abiding by social and } \\
\text { religious hierarchies }\end{array}$} & Obeying parental authority & 2 & 4 & 4 \\
\hline & & $\begin{array}{l}\text { Following religious } \\
\text { requirements }\end{array}$ & 7 & 6 & 3 \\
\hline & \multicolumn{2}{|l|}{ Total } & 9 & 10 & 7 \\
\hline \multirow{3}{*}{4} & \multirow[b]{2}{*}{ Health and hygiene } & Cleanliness of the body & 2 & 2 & 2 \\
\hline & & $\begin{array}{l}\text { Associated health risks \& } \\
\text { benefits }\end{array}$ & 6 & 7 & 7 \\
\hline & \multicolumn{2}{|l|}{ Total } & 8 & 9 & 9 \\
\hline \multirow{4}{*}{5} & \multirow{4}{*}{$\begin{array}{l}\text { Sexuality and } \\
\text { womanhood }\end{array}$} & Passage into womanhood & 2 & 2 & 2 \\
\hline & & Beauty & 2 & 2 & 2 \\
\hline & & Chaste sexual reputation & 9 & 7 & 6 \\
\hline & & Moral virtuousness & 3 & 3 & 3 \\
\hline & \multicolumn{2}{|l|}{ Total } & 16 & 14 & 13 \\
\hline \multirow{6}{*}{6} & \multirow{4}{*}{$\begin{array}{l}\text { Acceptability of practice } \\
\text { changes }\end{array}$} & Medicalisation & 11 & 10 & 11 \\
\hline & & Cut severity & 5 & 4 & 4 \\
\hline & & Decreased age & 2 & 2 & 2 \\
\hline & & Abandonment & 10 & 7 & 8 \\
\hline & \multicolumn{2}{|l|}{ Total } & 28 & 23 & 25 \\
\hline & \multicolumn{2}{|l|}{ OVERALL TOTAL } & 97 & 94 & 92 \\
\hline
\end{tabular}




\section{Appendix 3}

Table 3.1: Population-proportionate household-level study samples

\begin{tabular}{|c|c|c|c|c|c|}
\hline Regions & District & Sample size HH survey & Women & Men & \\
\hline & & 715 & 570 & 145 & \\
\hline Awdal & Borama & 137 & 110 & 27 & \multirow{6}{*}{$\begin{array}{l}\text { These samples by } \\
\text { gender was spread } \\
\text { across the regions' } \\
\text { randomly selected } \\
\text { districts }\end{array}$} \\
\hline Maroodi-Jeex & Hargeisa & 253 & 201 & 53 & \\
\hline Togdheer & Burco & 147 & 118 & 29 & \\
\hline Sool & Caynabo & 67 & 53 & 13 & \\
\hline Sanaag & Ceerigabo & 111 & 89 & 22 & \\
\hline Total & & 715 & 570 & 145 & \\
\hline
\end{tabular}

Table 3.2: Areas visited for data collection

\begin{tabular}{|c|c|c|c|}
\hline Regions & District & Urban & Rural \\
\hline \multirow{3}{*}{ Maroodi-Jeex } & \multirow{3}{*}{ Hargeisa } & Ga'an Libah & Xunbo-Wayne \\
\hline & & Ahmed Dhagax & Cuna-Qabad \\
\hline & & Kood Buur & Arabsiyo \\
\hline \multirow{3}{*}{ Awdal } & \multirow{3}{*}{ Borama } & Sh. Cali Jowhar & Caro-Garanuug \\
\hline & & Sh. Cismaan & Goraya-Cawl \\
\hline & & Sh. Makaahiil & Magaalo-Cad \\
\hline \multirow{3}{*}{ Togdheer } & \multirow{3}{*}{ Burco } & Faarah Oomar & Yiroobe \\
\hline & & Mohamed Ali & Bali Hiile \\
\hline & & Sh. Bashiir & Qoyta \\
\hline \multirow{3}{*}{ Sanaag } & \multirow{3}{*}{ Ceerigaabo } & Daalo & Kulmiye \\
\hline & & Kulmiye & Yufle \\
\hline & & Shacabka & Karin \\
\hline \multirow{3}{*}{ Sool } & \multirow{3}{*}{ Caynabo } & Garoonka & Wadaamo goo \\
\hline & & $\mathrm{MCH}$ & War idaad \\
\hline & & Stationka Caynabo & Oog \\
\hline
\end{tabular}




\section{Appendix 4}

Table 4.1: Urban and rural study samples

\begin{tabular}{|l|c|c|c|c|c|c|c|c|c|c|c|c|c|c|c|}
\hline & \multicolumn{2}{|c|}{ Sample } & W & M & W & M & W & M & W & M & W & M & W & M \\
\hline Region & Women & Men & \multicolumn{2}{|c|}{ Urban 1 } & \multicolumn{2}{|c|}{ Urban 2 } & \multicolumn{2}{|c|}{ Urban 3 } & \multicolumn{2}{|c|}{ Rural 1 } & \multicolumn{2}{c|}{ Rural 2 } & \multicolumn{2}{c|}{ Rural 3 } \\
\hline Awdal & 110 & 27 & 18 & 5 & 18 & 5 & 18 & 5 & 18 & 5 & 18 & 5 & 18 & 5 \\
\hline $\begin{array}{l}\text { Waqooyi } \\
\text { Galbeed }\end{array}$ & 201 & 53 & 34 & 9 & 34 & 9 & 34 & 9 & 34 & 9 & 34 & 9 & 34 & 9 \\
\hline Togdheeer & 118 & 29 & 20 & 5 & 20 & 5 & 20 & 5 & 20 & 5 & 20 & 5 & 20 & 5 \\
\hline Sool & 53 & 13 & 9 & 2 & 9 & 2 & 9 & 2 & 9 & 2 & 9 & 2 & 9 & 2 \\
\hline Sanaag & 89 & 22 & 15 & 4 & 15 & 4 & 15 & 4 & 15 & 4 & 15 & 4 & 15 & 4 \\
\hline
\end{tabular}

Note: ${ }^{*} \mathrm{~W}=$ Women ${ }^{*} \mathrm{M}=$ Men 